\title{
Organizational Dynamics Over the Business Cycle: A View on Jobless Recoveries
}

\author{
Kathryn Koenders and Richard Rogerson
}

\begin{abstract}
This paper proposes a new explanation for the apparent slow growth in employment during the past two recoveries. The authors' explanation emphasizes dynamics within growing organizations and the intertemporal substitution of organizational restructuring. A key implication of the analysis is that recoveries from recessions following long expansions will have slower employment growth. Empirical analysis shows that the recovery that began in 1970 also exhibited slow employment growth, consistent with this prediction of the analysis.
\end{abstract}

Federal Reserve Bank of St. Louis Review, July/August 2005, 87(4), pp. 555-79.

S ince the work of Burns and Mitchell (1946), economists who study business cycle fluctuations typically refer to the "business cycle facts" without need to reference a particular episode in a particular country. One of the accepted stylized facts of business cycle movements is that employment and output are strongly positively correlated, although employment lags output by about one quarter. The apparent slow growth of employment in the recoveries following the past two U.S. recessions (i.e., the so-called "jobless recovery" phenomenon) runs counter to this stylized fact. This paper suggests a possible explanation for this apparently anomalous behavior.

The two most recent recessions in the United States share a common property: Both followed unusually long expansions. Motivated by this observation, we propose an economic mechanism that links the speed at which employment increases during the recovery from a recession to the length of the expansion preceding the recession. ${ }^{1}$ This mechanism stresses the manner in which organizations seek to eliminate unneeded labor. Specifically, we assume that inefficiencies regarding the use of labor emerge over time within an organization. Eliminating these inefficiencies (a process we refer to as reorganizing) requires scarce organizational resources that must be diverted away from current production. This trade-off generates opportunities for intertemporal substitution, and we show that reorganization will be postponed to periods in which production is relatively low. It follows that after a long expansion, many more organizations have postponed reorganization. Because reorganization leads to the shedding of unnecessary labor and takes time, this gives rise to an extended period in which the economy sheds labor, thereby delaying the date at which aggregate employment begins to increase during the recovery.

The first part of this paper presents one formulation of a model of organizations that generates these effects. The core model should be seen as an extension of the Lucas (1978) span-of-control model and the Hopenhayn (1992) industry equilib-

1 As noted by Kliesen (2003), these two recessions are also relatively mild. Our theory does not address this regularity.

Kathryn Koenders is a doctoral student and Richard Rogerson is the Rondthaler Professor of Economics at the W.P. Carey School of Economics at Arizona State University. The authors thank Fernando Alvarez and conference participants and seminar participants at the Federal Reserve Banks of Atlanta, Cleveland, New York, and Philadelphia for comments. Richard Rogerson acknowledges support from the National Science Foundation.

(C) 2005, The Federal Reserve Bank of St. Louis. Articles may be reprinted, reproduced, published, distributed, displayed, and transmitted in their entirety if copyright notice, author name(s), and full citation are included. Abstracts, synopses, and other derivative works may be made only with prior written permission of the Federal Reserve Bank of St. Louis. 
rium model to allow for a richer set of dynamics within an organization. Although we focus on the implications for business cycles, we believe this model may also prove useful for examining plant- and firm-level dynamics more generally. The model is purposefully simplified to highlight the key economic trade-offs, and the analysis focuses on the qualitative nature of the interactions. The task of building a model suitable for quantitative analysis of the forces is left for future work. $^{2}$

Any theory that links the speed of the recovery in employment to the length of the preceding expansion would seem to be a viable candidate for explaining the anomalous behavior of employment following the past two recessions. However, because the recession of 1969-70 also followed an unusually long expansion, an obvious implication of any such theory is that a slow recovery of employment should also have been observed following this recession. The second part of the paper turns to this issue and argues that, when viewed from the perspective of our model, the behavior of employment in the 1970 recovery is in fact very similar to the behavior of employment in the recoveries of 1991 and 2001 and is qualitatively different from the behavior of employment in the other post-World War II recoveries.

One interpretation of our explanation is that the recent recessions do not represent counterexamples to the standard set of business cycle facts, but rather that the business cycle facts need to be modified somewhat to acknowledge that recoveries following long expansions exhibit somewhat different dynamics. There are, of course, other types of explanations that one might appeal to. For example, if one thought that it is only the two most recent recessions that appear different, one might consider the possibility that the business cycle facts are evolving and seek to understand what features of the economy are changing that would lead to the change in business cycle dynamics of employment. Schreft and Singh (2003) pursue this tack, arguing that increased flexibility in personnel policies are responsible

\footnotetext{
2 van Rens (2004) presents an alternative theory that stresses investment in organizational capital as a key factor in explaining the pace of employment growth coming out of a recession.
}

for the change. A second general class of explanations is to posit that the anomalous behavior of employment in any particular cycle is due to an additional shock or policy change that happens to coincide with the recovery. The work of Cole and Ohanian (2004) on employment during the second half of the Great Depression is exactly this type of explanation: They argued that employment did not recover as one would have expected because of the adoption of the New Deal policies. A third and related class of explanations stresses that the economic changes taking place in the background may influence the nature of cyclical episodes. Along these lines, a commonly heard explanation for the recent slow recovery of employment was that the world had become more uncertain, leading firms to postpone increases in employment. Another explanation in this class is that the current period involves a greater degree of structural change. Groshen and Potter (2003) examine data on sectoral employment shares and argue that this is the case. ${ }^{3}$ Andolfatto and MacDonald (2004) present a model in which certain types of technological change can generate this outcome. We do not compare our explanation with these others, but do note that the extent to which the 1970 recovery is viewed as being similar to the two most recent recoveries would cast some doubt on the theory that there is evolution in the business cycle facts.

The mechanism that we describe is related to others that have appeared in the literature, and it is of interest to note the similarities and differences. An old idea in the business cycle literature is that recessions are periods of restructuring. However, modern formulations of this idea, such as Lilien (1982), are based on the notion that the key element of restructuring is across organizations-in particular, that resources need to be reallocated across sectors. In contrast, our model does not stress the reallocation of resources from one organization to another but rather the restructuring that takes place within organizations that leads to the elimination of wasteful employment. Hall (1991) argued that recessions should be

\footnotetext{
3 See Aaronson, Rissman, and Sullivan (2004) for an argument against this interpretation.
} 
thought of as reorganizations, but the reorganizations that he stresses were really reallocations of labor across activities. As noted here previously, Groshen and Potter (2003) have stressed that the amount of reallocation needed may vary over time and be higher in some business cycle episodes than in others.

A second related literature is associated with the work of Caballero and Engel (1999) and Krusell and Smith (1998). Both papers consider the possibility that the distribution of individual state variables can influence how the economy responds to shocks. Caballero and Engel argue that the distribution of the difference between plant-level capital stocks and their ideal points was quantitatively significant for the response of the economy to shocks. Krusell and Smith examine how the distribution of asset holdings across consumers affects propagation of shocks. Qualitatively, our model emphasizes a similar channel, because we argue that the distribution of efficiencies of organizations matters for how the economy responds to shocks. However, despite the similarity, the mechanics are quite different. In particular, if carried over to the labor setting, the Caballero and Engel model cannot explain why aggregate demand for labor would continue to decrease in the face of positive aggregate shocks, a result that can emerge in our model and is central to accounting for the delayed increase in employment that accompanied the past two recoveries.

An outline of the next five sections follows: We describe our benchmark model, which captures the evolution of an individual organization over its life cycle. Then we consider how aggregate temporary shocks interact with the decisions of the organization and derive our key result: Organizations will concentrate reorganizations during periods with negative aggregate shocks. The last sections (i) discuss the implications of this finding for the cyclical properties of labor demand and (ii) carry out an empirical analysis of postwar business cycles to show that the recovery following the 1969-70 recession exhibits patterns for employment that are quantitatively very similar to those found in the two most recent recoveries.

\section{BENCHMARK MODEL: A LIFE CYCLE MODEL OF ORGANIZATIONAL DYNAMICS}

In this section we formulate a model of the life cycle of an organization. In the next section we will use this benchmark model to investigate how the resulting pattern of organizational dynamics may be affected by shocks that we interpret to be business cycle shocks. The goal of these two sections is to highlight a particular interaction between organizational dynamics and business cycle shocks. ${ }^{4}$ With this in mind, we purposefully work in a very simple setting to best highlight this interaction. We leave the development of a model that would be useful for a quantitative assessment of these interactions to future work.

The essence of the benchmark model is as follows. We view an organization as producing a differentiated product and therefore facing a downward sloping demand curve for its product. Our model captures the following stylized evolution of an organization over its life cycle: When an organization is first created it faces a relatively low demand for its product. But, over time, this situation may change. Some organizations fail and disappear, while others experience large increases in the demand for their product and hence grow. However, even those organizations that grow and become large will at some point experience decreases in their demand and eventually cease to exist.

The model that we describe here is one of an individual organization that faces stochastic demand for its product but takes all input prices as given, prices that remain constant over time. We assume that the organization maximizes the present discounted value of profits using a discount rate of $\beta$, which one can think of as 1 divided by the sum of 1 plus the interest rate. We now describe the specifics of the model in more detail.

\footnotetext{
4 Our model without aggregate shocks can also be viewed as extending the model of Hopenhayn (1992) to consider richer decisionmaking processes within organizations.
} 


\section{Koenders and Rogerson}

\section{Demand}

Let $P\left(y_{t}, \varepsilon_{t}\right)$ be the inverse demand faced by the organization in period $t$, where $y_{t}$ is the amount of output produced in the current period and $\varepsilon_{t}$ is a stochastic shock to the demand for the output of the organization. For a given value of $\varepsilon_{t}$, we assume that this function is twice continuously differentiable and strictly decreasing in $y$ and that the product $P(y, \varepsilon) y$ is strictly concave in $y$ and satisfies the boundary conditions:

$$
\lim _{y \rightarrow 0} \frac{d}{d y} P(y, \varepsilon) y=\infty \text {, and } \lim _{y \rightarrow \infty} \frac{d}{d y} P(y, \varepsilon) y<0 .
$$

The first condition will ensure that an organization that remains in existence will always want to produce a positive amount of output, and the second condition states that output can effectively be viewed as bounded for any given $\varepsilon$, because the organization will never produce beyond the point where revenues are decreasing in output.

We assume a very simple form for the stochastic process on $\varepsilon$. In particular, we assume that $\varepsilon_{t}$ takes on only one of two values, $\varepsilon^{s}$ or $\varepsilon^{l}$, where $\varepsilon^{s}<\varepsilon^{l}$, with the interpretation that $\varepsilon^{s}$ is the low demand state that will give rise to a small organization, while $\varepsilon^{l}$ is the high demand state that will give rise to a large organization. To generate the standard life-cycle profile of organization size, we assume that when an organization is first created it will have a value of $\varepsilon$ equal to $\varepsilon^{s}$ and that over time the state of demand may increase to $\varepsilon^{l}$. We simplify this process by assuming that the probability that $\varepsilon$ increases from $\varepsilon^{s}$ to $\varepsilon^{l}$ is given by the value $\pi^{l}$, which is assumed to be constant over time. We also assume that the process never transits from $\varepsilon^{l}$ back to $\varepsilon^{s}$. To capture the notion that state $\varepsilon^{l}$ is better than state $\varepsilon^{s}$, we assume that $P\left(y, \varepsilon^{l}\right)>$ $P\left(y, \varepsilon^{s}\right)$ for all positive values of $y$ and that

$$
\frac{d}{d y} P\left(y, \varepsilon^{l}\right) y>\frac{d}{d y} P\left(y, \varepsilon^{s}\right) y
$$

for all positive $y$ as well.

If the stochastic evolution of $\varepsilon$ just described were a complete description of the uncertainty facing a given organization, then all new organizations would eventually become "large" and remain that way forever. We incorporate the fact that organizations do not last forever by assuming that organizations face an exogenous probability of death and that this probability varies with the state of their demand, $\varepsilon$. In particular, we assume that an organization with demand state $\varepsilon^{i}$ faces a probability $\lambda^{i}$ of death. This assumption implies not only that organizations do not last forever, but also that not all new organizations will necessarily become "large." 5 We assume that the realizations of the random variables are independent.

Our assumption about timing is as follows. An organization that produced in period $t$ with demand state $\varepsilon^{i}$ finds out the realizations of the demand and death shocks at the beginning of period $t+1$ but before any decisions are made in period $t+1$.

\section{Production}

We assume that labor is the only factor of production. The production technology in our model has several key features, which we detail in several steps.

Scale Effects. We assume that there are different ways to organize production and that the optimal way to organize production depends on the scale of production. In general, one could imagine a large set of possible ways to organize production, but given that we are restricting attention to a model with two demand states we also assume that there are only two ways in which production can be organized. We refer to each different way to organize production as a distinct technology. We let $h^{i}(y)$ denote the labor necessary to produce output $y$ using technology $i$. Because we will implicitly restrict parameter values so that an organization with demand state $\varepsilon^{s}$ will always use technology 1 and an organization with demand state $\varepsilon^{l}$ will always use technology 2, we will also use $s$ and $l$ to index the two technologies. The idea is that technology 1 is better when producing at a small scale, whereas technology 2 is better when pro-

\footnotetext{
5 This specification amounts to assuming that there are three demand types, with the third state being an absorbing state in which the organization cannot sell any positive amount of output and still receive a positive price. We identify this third state with death of the organization.
} 
ducing at a large scale. We adopt the following functional forms for the two technologies. We assume that $h^{s}(y)=a_{s} y$ for all positive values of $y$, where $a_{s}>0$. The other technology is operable only above some minimum threshold scale, $\bar{y}$, and for $y \geq \bar{y}$ we assume that $h^{l}(y)$ takes the form $h^{l}(y)=a_{l} y$, where $a_{l}<a_{s}$. More generally we could specify that this technology can operate at a scale less than $\bar{y}$ but that the average product of labor is sufficiently low that no one would choose to operate it below scale $\bar{y}$. We assume free disposal of output, implying that an organization could choose to operate the large-scale technology but only sell a fraction of the output, though in our analysis we will implicitly assume that this never happens.

We assume that the organization hires labor in a competitive market and hence takes the wage rate as given. In what follows we normalize the wage rate to 1 .

Organizational Waste. An important goal for any organization is to use its resources efficiently. The large differences in measured productivity across organizations suggest that organizations vary in the degree to which they accomplish this. Inefficient use of resources may take several forms. We incorporate one particular form of inefficiency, which we refer to as waste. What we have in mind is that in any organization there is potentially some duplication of effort or unnecessary tasks being performed that affect labor productivity in an inframarginal way. In particular, in the context of the technologies described in the previous section, we assume that an organization with waste $\phi$ has labor requirement $h(y)+\phi$ rather than $h(y)$. The key feature of this waste is that it affects average labor productivity but not marginal labor productivity. One could obviously consider inefficiency that also serves to alter the slope of $h(y)$. Inefficiencies of this form are certainly plausible. We assume inefficiency only of the form as characterized by the parameter $\phi$ because it is this type of inefficiency that will be central to our analysis. We interpret this inefficiency as reflecting inefficiency in the organizational design and not inefficiency due to workers shirking, for example.

For our purposes there are two key issues associated with these inefficiencies. The first is where they come from, and the second is how organizations can eliminate them. Again, our formulation will be somewhat specialized to isolate a particular effect. In general, one could imagine that inefficiencies stochastically occur within any organization and that it takes organizational resources to get rid of them. One could also assume that organizations devote resources to these activities ex ante to reduce the likelihood that they arise. Our formulation relies on the notion that changes in organizational scale are likely to be associated with the appearance of inefficiencies because the organization is less likely to know how to best use resources as it moves to a new organizational structure. ${ }^{6}$ Motivated by this idea, we assume that all organizations operating the small-scale technology do so efficiently, but that whenever an organization switches from the small-scale technology to the large-scale technology it will necessarily move to a positive level of inefficiency that we denote by the parameter $\bar{\phi}$. That is, if an organization used technology $s$ in period $t-1$ and switches to technology $l$ in period $t$, then their labor requirement function will be $a_{l} y+\bar{\phi}$ for $\mathrm{y}$ $\geq \bar{y}$. We note that it would be straightforward to also assume that a new organization that is operating the small-scale technology for the first time also begins with an inefficiency, but we abstract from this possibility for simplicity. We assume that the level of inefficiency is known to the organization. Although one could consider interesting issues that arise from organizations not having complete information about the state of their efficiency and needing to learn over time about them, we abstract from them here.

Having described how inefficiencies arise, we now turn to the issue of how an organization can get rid of them. We adopt a simple and straightforward formulation. In particular, in any given period an organization makes a discrete decision about whether to try to eliminate inefficiency. Having done so, with probability $\pi^{e}$ the organization will decrease its inefficiency to zero in the following period, whereas with probability $1-\pi^{e}$

6 Bertschek and Kaiser (2001) present evidence from a data set of German firms that changes in productivity are linked with changes in organizational structure. 
the organization will experience no change in its level of inefficiency. Assuming that there is no improvement in efficiency, the organization can continue to try to get rid of the inefficiency in each subsequent period.

Our formulation assumes that a given organization makes stochastic transitions between two levels of efficiency. If we had a large number of organizations all with inefficiency $\bar{\phi}$ and they all continued to try to eliminate this inefficiency until successful, then the average level of inefficiency among this group of organizations would decrease monotonically and approach zero asymptotically. As we will see later in the analysis, this is the pattern that we want to generate. Of course, this pattern could also be generated by having each individual organization experience a monotonically decreasing level of inefficiency rather than the all-or-nothing form that we specify. We have chosen the all-or-nothing form of improvements to simplify the analysis of the model.

In the next subsection we describe in more detail the cost to the organization of trying to reduce its level of inefficiency. Note that we assume that there is no direct cost associated with changing from one technology to another. It would be straightforward to add such a cost but it is not central to the effects that we stress below. Last, our model is related to models of costly adjustment and models of organizational capital, so it is of interest to remark on these relationships. At a general level, the inefficiency associated with change of scale can obviously be interpreted as a form of adjustment cost. We note, however, that our specification differs from most specifications of adjustment costs because the cost does not necessarily disappear in the periods following the adjustment. That is, most models of adjustment costs assume a one-time cost associated with the adjustment, but here the cost is permanent unless the organization takes some actions. The restructuring that takes place within organizations in our model can also be interpreted as a form of investment in organizational capital. However, our model differs from many formulations of organizational capital in that we implicitly assume that this investment in organization capital is a substi- tute for labor input because it leads to a reduction in labor, whereas most analyses assume that increases in organizational capital lead to increases in the marginal product of labor.

The Role of the Manager. We assume that each organization has one manager and potentially many workers. The labor requirement functions described in the previous subsection should be thought of as specifying the required amount of nonmanagerial labor input. In this regard our model is similar to the standard spanof-control model of Lucas (1978). However, we deviate from that model by allowing a manager to choose between two primary uses of their time. In particular, we assume that managers can devote their time either to facilitating production or to trying to reduce inefficiency. We shall cast this choice as having the manager choose between "producing" or "reorganizing," which we will denote as $m=p$ and $m=r$, respectively. The cost of having managers devote time to reorganizing is that they are not able to focus on production. We model this cost as a decrease in the efficiency of labor used in the organization. In particular, we assume that if a manager of an organization using large-scale technology with inefficiency $\bar{\phi}$ devotes time to reorganization, then the labor requirement function becomes $(1+\bar{\eta}) h^{l}(y)+\bar{\phi}$, where $\bar{\eta}>0$ is the efficiency loss associated with the manager not focusing attention on production. The benefit of having the manager focus on reorganizing is that it makes it possible for the organization to be more efficient in the future. As this description makes clear, a key trade-off that a manager faces when making decisions about time allocation is between current efficiency and future expected efficiency. As we will see in the next section, it is this tradeoff and how it interacts with business cycle shocks that is at the heart of our analysis.

We assume a competitive market for (homogeneous) managers. The organization will therefore also take the managerial wage as given, which we also assume to be constant over time. Because an organization cannot function without a manager, managerial compensation is effectively a fixed per-period cost for the organization. We denote this wage by $w_{m}$. The only way that an organization can avoid having to hire a manager 
is to cease to exist. We assume that if an organization chooses this option that it cannot return in the future.

\section{The Organizational Life Cycle}

It is straightforward to formulate the optimization problem of the organization just depicted. We do it recursively. The state vector for the organization that remains alive is denoted by $s=(\varepsilon, \phi)$, where $\varepsilon$ is the state of demand for its product and $\phi$ is its level of inefficiency if it chooses to operate the large-scale technology. An organization is always born into the state $\left(\varepsilon_{s}, \bar{\phi}\right)$, which is to say that a new organization begins with demand in the low state and an inefficiency level of $\bar{\phi}$. Note that the level of inefficiency begins at $\bar{\phi}$ because, if a new organization were to use the large-scale technology, it would be faced with the inefficiency. But, as noted earlier, as long as it chooses to operate the small-scale technology, it can do so without experiencing any inefficiency. In each period, after observing its current state variable, if the organization remains alive it faces three choices: which technology to use ( $i=s$ or $1)$, how much output to produce $(y)$, and how to allocate the manager's time ( $m=p$ or $r$ ). Given the organization's state vector and choices for each of these decisions, we can determine the current revenues net of payments to nonmanagerial labor that would accrue to the organization, which we will denote by $R(\varepsilon, \phi, i, y, m)$. This function takes the following form:

$$
\begin{aligned}
& R(\varepsilon, \phi, i, y, m) \\
& =P(y, \varepsilon) y-\left(1+\bar{\eta} I_{m=r}\right) h^{i}(y)-I_{i=l} \phi-w_{m},
\end{aligned}
$$

where $I_{m=r}$ is the indicator function for $m=r$ (i.e., the manager reorganizes) and $I_{i=1}$ is the indicator function for using the large-scale technology.

It is now easy to write the Bellman equation for the maximization problem faced by the organization:

(2) $V(\varepsilon, \phi)=\max \left\{0, \max _{i, y, m}\left[\begin{array}{l}R(e, \phi, i, y, m) \\ +\beta\left(1-\lambda^{i}\right) E V\left(\varepsilon^{\prime}, \phi^{\prime}\right)\end{array}\right]\right\}$,

where the outer max reflects the decision of whether to remain active and the inner max reflects the optimal choices, assuming that the organization remains active. We have assumed that if the organization ceases to exist, either through choice in the current period or because of a death shock in the next period, all future returns will be zero. The expectation operator $E$ incorporates two elements. First it incorporates the dynamics in the demand state $\varepsilon$, and second it incorporates the dynamics in the level of inefficiency if the organization chooses to have the manager devote time to reorganization.

Given our assumptions thus far, we cannot rule out some rather extreme or degenerate outcomes that are of little interest. We describe some of these now. In what follows we do not offer any specific conditions on the model specification to rule out these outcomes, but do note intuitively what parameters would be relevant in ruling out certain outcomes.

It is possible that a newly created organization cannot earn positive expected lifetime profits and hence will choose to shut down. In particular, as noted previously, the managerial wage acts like a fixed cost of being in operation, and it is well known that in a model with a fixed cost it is not enough to guarantee positive net revenues from the variable factors, as our earlier assumption on $P$ does. Of course, if a newly created organization is choosing to shut down and there is some cost associated with creating an organization in the first place, then this would imply that new organizations are never created. In an equilibrium context in which consumption is infinitely valued at the margin when consumption is zero, such an outcome could not be an equilibrium outcome. In view of this, it is natural to assume that wages are sufficiently low relative to the price of output that new firms choose to operate. Given our assumptions on the price function, $P$, it follows that if the expected present discounted value of profits is positive for a newly created organization, then it is positive for any feasible state vector. This property does not necessarily imply that the organization will have positive current-period profits in all states; it is possible that a new organization remains active only because of the possibility of transiting to the higher demand state and that the higher demand state is the only state 
that is profitable in a static sense. Given our assumptions on $P$, however, it is true that if an organization remains active it will always choose to produce a positive amount of output, even if current-period profits are negative.

The model has been constructed to focus on the change in scale of production and the associated change in organization structure that occurs as organizations successfully mature. Given a price function, $P$, however, if the value of $\bar{y}$ is sufficiently large then no organization will ever choose to operate the large-scale technology; if $\bar{y}$ is too small, then all organizations will choose to operate the large-scale technology. In the context of our model, neither of these cases is particularly interesting. So, in what follows, we assume that it is optimal for an organization in demand state $\varepsilon^{s}$ to operate the small-scale technology and for an organization in the demand state $\varepsilon^{l}$ to operate the large-scale technology. We note, as a feature of our specification, that it is not possible to eliminate future inefficiency while currently operating the small-scale technology. It follows that, even if an organization decides to reorganize and thereby experiences the current loss of efficiency associated with $\eta$, the organization will still choose to operate the large-scale technology.

Last, it is also possible that the values of $\phi$ and $\bar{\eta}$ are such that no organization would ever choose to reorganize. This could happen if the level of inefficiency (i.e., $\phi$ ) is sufficiently small relative to the foregone productivity (i.e., $\bar{\eta}$ is large) or the probability of failure in reorganization (i.e., $1-\pi^{e}$ ). Conversely, if the size of the inefficiency is sufficiently large relative to the cost of eliminating it, then an organization would always choose to reorganize. Because the case of no reorganization is not very interesting in the context of our model, we assume in what follows that we are in a region of parameter space in which organizations do sometimes choose to reorganize.

Conditional on assuming that a newly created organization chooses to remain in existence, that organizations in the low (high) demand state operate the small- (large-) scale technology, and that organizations sometimes choose to eliminate inefficiency, it is fairly easy to characterize the life cycle dynamics that emerge. In particular, any newly created organization will operate the small-scale technology and hire an amount of labor that we denote by $h^{s}$, producing output denoted by $y^{s}$. Over time there are three things that may happen to this organization. It may receive a shock and cease to exist, it may remain in the same position and hence continue to hire $h^{s}$ workers, or it may experience a shock that increases its demand to the high state.

If it is sometimes optimal to try to eliminate inefficiency, then because the organization's problem is recursive, it must be optimal to do it the first time the organization reaches the high demand state. While in the high state and reorganizing, the organization is employing the largescale technology and hires labor that we denote by $h^{r}$, producing output denoted by $y^{r}$. Even though the manager's devotion of time to reorganizing lowers the marginal product of labor, it still must be the case that $h^{r}>h^{s}$. To see this, note the following. First, this organization must be producing at least $\bar{y}$ units of output, which must exceed the amount of output produced in the low demand state; otherwise it would not have been optimal to use the small-scale technology in the low demand state. Now, if it was possible to produce more output with less labor, then the organization could have chosen this combination in the previous state and chosen not to sell all of the output produced. It follows that $h^{r}$ must exceed $h^{s}$. It follows that if an organization experiences an improvement in its demand state, it increases both its labor input and its output. Note that we cannot say anything about what happens to average labor productivity. Productivity will depend on the magnitudes of the parameters $\bar{\eta}$ and $\bar{\phi}$.

An organization in the high demand state that is reorganizing can in turn experience three different transitions. First, it may receive a bad shock and cease to exist. Second, it may be unsuccessful in eliminating inefficiency and remain in the same state, in which case it chooses the same actions again. Third, it may be successful in eliminating the inefficiency. We denote the levels of $y$ and $h$ that result in this case as $h^{l}$ and $y^{l}$. How do the values of $h^{l}, y^{l}$ and $y^{l} / h^{l}$ compare with the corresponding values from earlier in the life cycle? The first-order condition for current-period choice of output combined with our assumptions on $P$ implies that output will definitely increase when 
the manager focuses on production rather than reorganization. This occurs because the term $(1+\bar{\eta})$ goes away from the first-order condition. However, it is ambiguous whether this leads to an increase or decrease in $h$, for two reasons. First, even if the only effect were the improved efficiency associated with the managerial time allocation, the effect on labor, as opposed to output, will depend on the elasticity of the demand function. Second, the elimination of the inefficiency measured by $\bar{\phi}$ necessarily implies a decrease in labor in the amount of $\bar{\phi}$. However, although the effect on $h$ is ambiguous, it is easy to see that independently of what happens to $h$, average labor productivity will necessarily increase.

Although with our implicit assumptions on parameter values that the organization will never choose to postpone reorganization once it reaches the high demand state, we can still ask what levels of $h$ and $y$ would be optimal if it chose to do so. Denote these levels by $h^{p}$ and $y^{p}$. We ask how $h^{p}$ and $h^{l}$ compare. In making this comparison we are assuming that the current-period marginal efficiencies are the same because in both cases the manager is focusing on production. Given our formulation, it follows that output will be the same in each case ( i.e., $y^{p}=y^{l}$ ). However, because of the waste in the former case, we know that $h^{p}>h^{l}$, which will be of particular interest later because it states that an inefficient firm that chooses to postpone reorganization will necessarily shed workers in the future.

As a final remark in this section, we note that our model emphasizes the restructuring that accompanies growth of an organization. It seems equally plausible that restructuring within shrinking organizations would also be of importance. For the implications that we stress, we believe that similar results would emerge from this situation as well, so we have chosen to focus on growing organizations purely for simplicity.

\section{THE MODEL WITH TEMPORARY SHOCKS}

The previous model considered the decisionmaking of an organization over its life cycle. The only shocks in that model were highly persistent, and we interpreted them to be organization specific. In this section we add purely temporary shocks to the model and examine how these temporary shocks influence the life cycle dynamics that we studied earlier. Although our model is purely decision theoretic, we will interpret the i.i.d. shocks that we introduce as reflecting (aggregate) business cycle shocks.

Formally, we assume a second shock that influences demand; for simplicity we assume that this shock is multiplicative, so that we write the inverse demand function facing the organization as $\varepsilon_{2 t} P\left(y_{t}, \varepsilon_{1 t}\right)$, where $P$ is the same function as described earlier, $\varepsilon_{1 t}$ is the shock that we previously labeled as $\varepsilon_{t}$, and $\varepsilon_{2 t}$ is an i.i.d. shock that is drawn from a distribution with $\operatorname{cdf} F\left(\varepsilon_{2}\right)$. We assume that realizations of $\varepsilon_{2}$ lie in the interval $\left[\varepsilon_{\min }, \varepsilon_{\max }\right]$ and that this interval contains 1 in its interior. Note that if $\varepsilon_{2 t}=1$ for all $t$, then the model is identical to that considered previously. All other aspects of the environment are left unchanged.

Proceeding as before, we define the revenue associated with decisions in a particular state as $R\left(\varepsilon_{1}, \varepsilon_{2}, \phi, i, y, m\right)$. This function takes the following form:

$$
\begin{aligned}
& R\left(\varepsilon_{1}, \varepsilon_{2}, \phi, i, y, m\right) \\
& =\varepsilon_{2} P\left(y, \varepsilon_{1}\right) y-\left(1+\bar{\eta} I_{m=r}\right) h^{i}(y)-I_{i=l} \phi-w_{m},
\end{aligned}
$$

where $I_{m=r}$ is the indicator function for $m=r$ (i.e., the manager reorganizes) and $I_{i=l}$ is the indicator function for using the large-scale technology. It is immediate that both $R$ and $R_{V}$ are increasing in $\varepsilon_{2}$.

It is again easy to write the Bellman equation for the maximization problem faced by the organization:

$$
V\left(\varepsilon_{1}, \varepsilon_{2}, \phi\right)=\max \left\{0, \max _{i, y, m}\left[\begin{array}{l}
R\left(\varepsilon_{1}, \varepsilon_{2}, \phi, i, y, m\right) \\
+\beta\left(1-\lambda^{i}\right) E V\left(\varepsilon_{1}^{\prime}, \varepsilon_{2}^{\prime}, \phi^{\prime}\right)
\end{array}\right]\right\} .
$$

For future reference it is worthwhile to elaborate on the expected value term in more detail. As noted earlier, this expectation takes into account the evolution of the exogenous shocks as well as the evolution of the inefficiency variable in response to the decision about reorganization. If $\varepsilon_{1}=\varepsilon^{s}$, then the only value of $\phi$ of interest is $\phi=\bar{\phi}$. 
Assuming this configuration plus an arbitrary value for $\varepsilon_{2}$, the term for the next period's value in the Bellman equation becomes

$$
\begin{aligned}
& \beta\left(1-\lambda^{i}\right) E V\left(\varepsilon_{1}^{\prime}, \varepsilon_{2}^{\prime}, \phi^{\prime}\right) \\
& =\beta\left(1-\lambda^{s}\right)\left[\begin{array}{c}
\pi^{l} \int V\left(\varepsilon^{l}, \varepsilon, \bar{\phi}\right) d F(\varepsilon) \\
+\left(1-\pi^{l}\right) \int V\left(\varepsilon^{s}, \varepsilon, \bar{\phi}\right) d F(\varepsilon)
\end{array}\right] .
\end{aligned}
$$

If the organization has $\varepsilon_{1}=\varepsilon^{l}$, then the only efficiency value of interest is still $\phi=\bar{\phi}$, because otherwise there is no need for a decision about reorganization and the problem becomes static. For an arbitrary value of $\varepsilon_{2}$, if the organization decides to reorganize, then the future term in the Bellman equation becomes

$$
\begin{aligned}
& \beta\left(1-\lambda^{i}\right) E V\left(\varepsilon_{1}^{\prime}, \varepsilon_{2}^{\prime}, \phi^{\prime}\right) \\
& =\beta\left(1-\lambda^{l}\right)\left[\begin{array}{r}
\pi^{e} \int V\left(\varepsilon^{l}, \varepsilon, 0\right) d F(\varepsilon) \\
+\left(1-\pi^{e}\right) \int V\left(\varepsilon^{l}, \varepsilon, \bar{\phi}\right) d F(\varepsilon)
\end{array}\right]
\end{aligned}
$$

whereas, if it chooses not to reorganize, then the same term becomes

$$
\beta\left(1-\lambda^{i}\right) E V\left(\varepsilon_{1}^{\prime}, \varepsilon_{2}^{\prime}, \phi^{\prime}\right)=\beta\left(1-\lambda^{l}\right) \int V\left(\varepsilon^{l}, \varepsilon, \bar{\phi}\right) d F(\varepsilon) .
$$

As was true in the previous subsection, depending on parameter values there are various forms that the optimal decision rules may take. We modify our previous assumptions marginally, so we now assume that when $\varepsilon_{1}=\varepsilon^{s}$ the organization will choose to remain active independently of the value of $\varepsilon_{2} \cdot{ }^{7}$ We furthermore assume that when an organization experiences an increase in its demand state from $\varepsilon^{s}$ to $\varepsilon^{l}$ that there is at least some interior value of $\varepsilon_{2}$ for which the organization would choose to reorganize.

Finally, we also place an implicit assumption on the size of the shocks to $\varepsilon_{1}$ and $\varepsilon_{2}$. In particular we assume that life-cycle shocks are much larger than business-cycle shocks. The significance of this is that we assume that when $\varepsilon_{1}=\varepsilon^{s}$ the organization does not wish to operate the large-scale

\footnotetext{
7 More generally, it would be straightforward to allow for the possibility that the organization will not remain in operation for all realizations of $\varepsilon_{2}$. In this case there will be a reservation value of $\varepsilon_{2}$ that dictates whether the organization remains.
}

technology independently of the realization of $\varepsilon_{2}$. Similarly, we assume that when $\varepsilon_{1}=\varepsilon^{l}$ the organization never chooses to operate the small-scale technology independently of the realization of $\varepsilon_{2}$. This model is identical to the model of the previous section if we assume that $\varepsilon_{\min }=\varepsilon_{\max }=1$. It follows that, if the previous model implies technology $i$ is operated only in demand state $i$, this model will also generate this result if the range of $\varepsilon_{2} \mathrm{~s}$ is not too large.

We are now able to prove our main result, which is that the decision to reorganize when in state $\left(\varepsilon^{l}, \varepsilon_{2}, \bar{\phi}\right)$ is characterized by a reservation value of $\varepsilon_{2}$, with the property that it is optimal to reorganize if $\varepsilon_{2}<\varepsilon_{2}^{*}$, and not to reorganize if $\varepsilon_{2}>\varepsilon_{2}^{*}$. The intuition for the result is simple: It basically reflects intertemporal substitution of reorganization. Reorganization imposes a cost today in terms of foregone efficiency of labor, but offers a future gain in reducing waste. If $\varepsilon_{2}$ is i.i.d., then future gains are the same independently of the current value of $\varepsilon_{2}$. But, we will show that the currentperiod cost of reorganizing is increasing in the amount of production desired in the event of not reorganizing, which in turn is increasing in $\varepsilon_{2}$.

We now establish these results. Consider an organization in state $\left(\varepsilon^{l}, \varepsilon_{2}, \bar{\phi}\right)$. Let $y^{P}$ denote the optimal level of production if the organization were to choose not to reorganize, and let $y^{r}$ denote the optimal level of production were the organization to choose to reorganize. Conditional on deciding whether to reorganize, note that the resulting decision about the optimal choice of $y$ is static and can be represented as

(8) $W\left(\varepsilon_{2}, \eta\right)=\max _{y}\left\{\varepsilon_{2} P\left(y, \varepsilon^{l}\right) y-(1+\eta) h(y)\right\}$,

where $\eta$ takes on the value 0 in the event of $m=p$ and $\eta=\bar{\eta}$ in the event that $m=r$. We denote the optimal choice of $y$ as $y\left(\varepsilon_{2}, \eta\right)$. Note that the firstorder condition that defines this function is

$$
\varepsilon_{2}\left[y P_{1}\left(y, \varepsilon^{l}\right)+P\left(y, \varepsilon^{l}\right)\right]=(1+\eta) h^{\prime}(y) .
$$

Given our assumptions, it follows trivially that the optimal value of $y$ is increasing in $\varepsilon_{2}$ and decreasing in $\eta$.

Let $V^{P}\left(\varepsilon^{l}, \varepsilon_{2}, \bar{\phi}\right)$ and $V^{r}\left(\varepsilon^{l}, \varepsilon_{2}, \bar{\phi}\right)$ be the resulting optimal values obtained from choosing not to 
reorganize and to reorganize, respectively, assuming that output is chosen optimally in each case. Now consider the difference between these two values. Using $V^{P}$ and $V^{r}$ to denote these functions, direct substitution gives

(10)

$$
\begin{aligned}
& V^{p}\left(\varepsilon^{l}, \varepsilon_{2}, \bar{\phi}\right)-V^{r}\left(\varepsilon^{l}, \varepsilon_{2}, \bar{\phi}\right)=R^{p}-R^{r}+\beta\left(1-\lambda^{l}\right) \\
& \left\{\begin{array}{c}
\int V\left(\varepsilon^{l}, \varepsilon_{2}, \bar{\phi}\right) d F(\varepsilon) \\
\left.-\left[\begin{array}{c}
\pi^{e} \int V\left(\varepsilon^{l}, \varepsilon_{2}, 0\right) d F(\varepsilon) \\
+\left(1-\pi^{e}\right) \int V\left(\varepsilon^{l}, \varepsilon_{2}, \bar{\phi}\right) d F(\varepsilon)
\end{array}\right]\right\},
\end{array}\right.
\end{aligned}
$$

where we have written $R^{p}=R\left(\varepsilon^{l}, \varepsilon_{2}, \bar{\phi}, 1, y^{P}, p\right)$ and $R^{r}=R\left(\varepsilon^{l}, \varepsilon_{2}, \bar{\phi}, l, y^{r}, r\right)$. Note that the value of the terms involving integrals are all independent of $\varepsilon_{2}$. Denote these terms by the constant $A$. Moreover, the difference in the two revenues can be reduced to

$$
R^{p}-R^{r}=W\left(\varepsilon_{2}, 0\right)-W\left(\varepsilon_{2}, \bar{\eta}\right) .
$$

It follows that equation (10) can be written as

$$
\begin{aligned}
& V^{P}\left(\varepsilon^{l}, \varepsilon_{2}, \bar{\phi}\right)-V^{r}\left(\varepsilon^{l}, \varepsilon_{2}, \bar{\phi}\right) \\
& =\left[W\left(\varepsilon_{2}, 0\right)-W\left(\varepsilon_{2}, \bar{\eta}\right)\right]+A .
\end{aligned}
$$

This equation is intuitive. The term in square brackets is the current-period cost of reorganizing: It represents the loss in current revenue associated with having the manager devote time to reorganizing. The term $A$ is the future benefit to reorganizing. Given our assumption, this is simply a positive number that is independent of $\varepsilon_{2}$.

We can now easily show that this difference is increasing in $\varepsilon_{2}$. It is sufficient to show that the term in square brackets is increasing in $\varepsilon_{2}$. Differentiation gives

$$
\frac{d}{d \varepsilon}\left[W\left(\varepsilon_{2}, 0\right)-W\left(\varepsilon_{2}, \bar{\eta}\right)\right]=W_{1}\left(\varepsilon_{2}, 0\right)-W_{1}\left(\varepsilon_{2}, \bar{\eta}\right),
$$

so it is sufficient to show that $W_{12}<0$. By definition,

$$
\begin{aligned}
& W\left(\varepsilon_{2}, \eta\right) \\
& =\varepsilon_{2} P\left(y\left(\varepsilon_{2}, \eta\right)\right) y\left(\varepsilon_{2}, \eta\right)-(1+\eta) h\left(y\left(\varepsilon_{2}, \eta\right)\right) .
\end{aligned}
$$

Using the envelope condition, we have that

$$
W_{2}\left(\varepsilon_{2}, \eta\right)=-h\left(y\left(\varepsilon_{2}, \eta\right)\right)<0 .
$$

It then follows that

$$
W_{12}\left(\varepsilon_{2}, \eta\right)=-h^{\prime}\left(y\left(\varepsilon_{2}, \eta\right)\right) y_{1}\left(\varepsilon_{2}, \eta\right) .
$$

Since $h$ is increasing and the solution for $y$ is increasing in $\varepsilon_{2}$, it follows that $W_{12}<0$ and hence $V^{P}\left(\varepsilon^{l}, \varepsilon_{2}, \bar{\phi}\right)-V^{r}\left(\varepsilon^{l}, \varepsilon_{2}, \bar{\phi}\right)$ is increasing in $\varepsilon_{2}$. If the benefit to not reorganizing is monotonic in $\varepsilon_{2}$, it follows that the optimal reorganization strategy is to employ a reservation value, as previously stated.

If the reservation value is equal to $\varepsilon_{\max }$ (i.e., the upper support of the distribution of the temporary shocks), then the organizational dynamics in this model are qualitatively the same as in the previous subsection. That is, whenever a small organization gets an improvement in their idiosyncratic demand state $\varepsilon_{1}$, they immediately choose to reorganize and continue to do so until the reorganization is successful. Fluctuations in $\varepsilon_{2}$ will lead to additional fluctuations in their labor input and output, but the life-cycle dynamics will be similar.

However, if the reservation value $\varepsilon_{2}^{*}$ is interior to the interval $\left[\varepsilon_{\min }, \varepsilon_{\max }\right.$ ], then qualitatively different dynamics can emerge. In this scenario, if an organization in the small idiosyncratic demand state receives a shock that raises it to the large idiosyncratic demand state, the organization may or may not decide to reorganize at that point. In particular, if $\varepsilon_{2}$ is sufficiently high, then the organization will choose to postpone the decision to reorganize to take advantage of the current temporarily high demand. As stated earlier, the organization will engage in intertemporal substitution of managerial actions. And, following from our discussion of the previous model, we know that an organization that chooses to postpone reorganization will necessarily employ less labor in the future when it does successfully reorganize, even holding the value of $\varepsilon_{2}$ constant.

\section{Extension to the Case of Persistent Shocks}

The previous analysis has assumed that the shock $\varepsilon_{2}$ is i.i.d. over time. Of course, if one wants 
to think of the $\varepsilon_{2}$ shock as proxying for business cycle movements in the demand faced by an individual organization, then the i.i.d. assumption is not very appealing. A well-documented property of business cycles is that they are persistent, in the sense that if the economy is above trend today then we also expect it to be above trend next period. In view of this, it is of interest to ask whether our result about the reservation value will extend to the case of persistent shocks. In fact, the argument is easily extended.

In the i.i.d. case, we argued that the current cost of reorganizing is increasing in the current value of $\varepsilon_{2}$ and that the expected future benefit of reorganizing is independent of the current-period value of $\varepsilon_{2}$. The first statement is independent of whether the realizations of $\varepsilon_{2}$ are i.i.d. or not. However, a key observation about the structure of our model is that the benefit to successful reorganization is in fact independent of future realizations of $\varepsilon_{2}$. The reason for this is that, in our model, successful reorganization does not influence the marginal product of labor, and as a result an efficient organization and an inefficient organization will choose the same level of output conditional on having the same managerial time allocation. The only effect on profit is from saving labor in the amount of $\bar{\phi}$ for each future period that the organization remains in existence, and this saving is independent of all future realizations of $\varepsilon_{2}$.

The additional issue that needs to be addressed in the context of a model with persistent shocks to $\varepsilon_{2}$ is the following: An organization faced with a current realization of $\varepsilon_{2}$ can also consider the possibility of waiting a period to reorganize. If the benefit from waiting increases as $\varepsilon_{2}$ decreases, then the reservation property might not be preserved. In the i.i.d. case, the benefit from waiting is actually increasing in $\varepsilon_{2}$, because next period's expected one-period cost of reorganizing is independent of $\varepsilon_{2}$; thus, a higher current value of $\varepsilon_{2}$ indicates lower expected costs in the future, whereas a low value of $\varepsilon_{2}$ indicates higher expected costs in the future.

With this in mind we can present the alternative characterization of the decision to reorganize. In particular, let $C(\varepsilon)=W(\varepsilon, 0)-W(\varepsilon, \bar{\eta})$ be the gain this period from not reorganizing. Let
$G=\beta \pi^{e} \bar{\phi} /\left(1-\beta\left(1-\lambda^{I}\right)\right)$ be the (expected) gain from choosing to reorganize today. Letting $H(\varepsilon)$ be the benefit of today's managerial choice relative to reorganizing today, we have that $H(\varepsilon)$ satisfies

$$
H(\varepsilon)=\max \left\{C(\varepsilon)+\beta \int H\left(\varepsilon^{\prime}\right) F\left(d \varepsilon^{\prime}, \varepsilon\right), 0\right\},
$$

where the first term indicates the gain from not reorganizing today and the second term indicates that if the manager chooses to reorganize then the gain is clearly zero. We know that $C(\varepsilon)$ is increasing in $\varepsilon$ from our previous analysis. If we knew that the term $C(\varepsilon)+\beta \int H\left(\varepsilon^{\prime}\right) F\left(d \varepsilon^{\prime}, \varepsilon\right)$ was increasing in $\varepsilon$, the current realization of the shock, then we could easily conclude that the reservation property holds. As stated earlier, note that if $\varepsilon$ is i.i.d., then the integral is independent of $\varepsilon$ and the property holds based on the property of $C$. However, finding conditions under which the integral is increasing in $\varepsilon$ is a standard problem in dynamic stochastic models. In particular, if we assume that

$$
\int g\left(\varepsilon^{\prime}\right) F\left(d \varepsilon^{\prime}, \varepsilon\right)
$$

is increasing in $\varepsilon$ for any increasing function, then we can easily show that the value function $H$ will in fact be increasing and hence that the integral has the desired property.

Loosely speaking, a process for $\varepsilon_{2}$ that implied mean reversion would tend to satisfy this property. This is because a high value of $\varepsilon_{2}$ today implies that future values of $\varepsilon_{2}$ will be lower, implying that it is beneficial to wait to reorganize. On the other hand, a very low value of $\varepsilon_{2}$ today implies that future values of $\varepsilon_{2}$ will be higher, implying that there is greater incentive to reorganize today rather than in the future.

We conclude that the reservation value property for the optimal reorganization decision will also hold in the case of persistent shocks under reasonable conditions.

\section{IMPLICATIONS FOR BUSINESS CYCLE DYNAMICS}

Our formal analysis has considered only the decision problem of an individual organization that takes demand for its product as given, assum- 
ing that wages for workers and managers and the real interest rate are constant over time. Such a model can be cast in an industry equilibrium setting, as in Hopenhayn and Rogerson (1993), in which the organizational dynamics that we describe can capture the steady-state dynamics of a general equilibrium model in which all shocks are idiosyncratic (i.e., there are no aggregate shocks). If one introduces aggregate shocks into such a model, then one would need to take into account the effect that these shocks have on wage rates and the real interest rate. Veracierto (2002) and Thomas (2002) are examples of models in which these general equilibrium effects are considered. Hence, in its current form the model is really not appropriate to discuss how the economy responds to aggregate shocks. Nonetheless, in this section we want to discuss some potential effects suggested by previous analysis for business cycle dynamics. We leave development of the appropriate framework and the associated formal analysis for future work.

Consider the following situation. We have a unit mass of entry of new organizations each period, each of which enters into the individual state $\left(\varepsilon^{s}, \bar{\phi}\right)$. We consider the $\varepsilon_{2}$ shock to be common to all organizations, while the $\varepsilon_{1}$ shock is idiosyncratic, and trace out the evolution of the economy assuming that wage rates and the interest rate remain constant. The first observation that we want to stress is that the aggregate state of this economy will be the realization of the aggregate shock $\varepsilon_{2}$ and the distribution of organizations across individual states. Entering a given period there are three types of organizations: those that are in the state $\left(\varepsilon^{s}, \bar{\phi}\right)$ (which we call type 1$)$, those that are in the state $\left(\varepsilon^{l}, \bar{\phi}\right)$ (which we call type 2 ), and those that are in the state $\left(\varepsilon^{l}, 0\right)$ (which we call type 3 ). We let $\mu_{i}$ be the mass of firms in each of the three states. The evolution of the $\mu_{i}$ s is affected by the realization of the aggregate shock because it determines whether organizations in state 2 will be reorganizing, thereby influencing the probability that an organization transits to state 3 . In particular, let $\mu_{i t}$ be the distribution of active organizations in period $t$. Then, if $\varepsilon_{2 \mathrm{t}}>\varepsilon_{2}^{*}$, we have the following:

$$
\begin{aligned}
& \mu_{1 t+1}=\left(1-\lambda^{s}-\pi^{l}\right) \mu_{1 t}+1 \\
& \mu_{2 t+1}=\left(1-\lambda^{I}\right) \mu_{2 t}+\pi^{l} \mu_{1 t} \\
& \mu_{3 t+1}=\left(1-\lambda^{I}\right) \mu_{3 t} .
\end{aligned}
$$

If, on the other hand, we have $\varepsilon_{2 t}<\varepsilon_{2}^{*}$, then the distribution will evolve according to

$$
\begin{aligned}
& \mu_{1 t+1}=\left(1-\lambda^{s}-\pi^{l}\right) \mu_{1 t}+1 \\
& \mu_{2 t+1}=\left(1-\lambda^{l}-\pi^{e}\right) \mu_{2 t}+\pi^{l} \mu_{1 t} \\
& \mu_{3 t+1}=\left(1-\lambda^{l}\right) \mu_{3 t}+\pi^{e} \mu_{2 t} .
\end{aligned}
$$

Two simple conclusions can be drawn from these laws of motion. First, note that the law of motion for $\mu_{1 t}$ is independent of the realization of $\varepsilon_{2}$. It follows that, if entry is constant as we have assumed, the value of $\mu_{1}$ will approach a constant and will not be affected by realizations of $\varepsilon_{2}$. The constant fraction of type 1 organizations is easily computed to be $\lambda^{l} /\left(\lambda^{l}+\pi^{l}\right)$. The second point to note is that the remaining mass of organizations will be split between type 2 and type 3 organizations and that this division will depend on the history of the $\varepsilon_{2}$ realizations. Specifically, if $\varepsilon_{2}$ remains above $\varepsilon_{2}^{*}$, then there is a greater buildup of type 2 organizations at the expense of type 3 organizations. It follows that the longer the aggregate shock remains above the reservation value, the greater will be the buildup of type 2 organizations. In what follows, we illustrate the potential effects that this can have on how the economy responds to subsequent shocks.

\section{A Reduced-Form Example}

For present purposes, the most effective way to illustrate the interaction between the distribution of organizations and the response of the economy to a given sequence of aggregate shocks is with a very specific reduced-form example. Consider an economy at time 0 with unit mass of organizations that are distributed across types. We assume that the stochastic process for $\varepsilon_{2}$ has a sequence of realizations of the following form. In period 0 the economy is hit by a (very) negative value of $\varepsilon_{2}$ but, subsequent to this, experiences a constant and gradual increase back toward its unconditional mean value. We assume that it takes the economy 20 periods to reach this value, at 
which time it remains there. This type of realization could be thought of as tracing out the impulse response function in the presence of a meanreverting process.

We assume the following reduced-form properties in our example. First, we assume that reorganization is optimal for this entire range of realized $\varepsilon_{2}$ values. Second, we assume that when an organization reorganizes successfully, the effect on labor input is a decrease of $e^{f}$, holding $\varepsilon_{2}$ constant, and is independent of the level of $\varepsilon_{2}$. Third, we assume that, for each period in which $\varepsilon_{2}$ is increasing, the aggregate effect of this on labor input is an increase in labor input of $e^{h}$, which we assume is distributed across organizations according to size. ${ }^{8}$ We assume that in period 0 a small organization employs 10 workers and that a large reorganized organization employs 100 workers. By assumption, a large organization in the process of reorganizing will employ $100+e^{f}$ workers. The probabilities $\pi^{l}, \pi^{e}, \lambda^{s}$, and $\lambda^{l}$ are as before.

Our goal here is to illustrate the potential for the initial distribution of organizations to influence the resulting response of employment to a given sequence of shocks. With this in mind, we simulate the implied path of aggregate employment for several different initial conditions. As already noted above, with a constant rate of entry of new organizations, asymptotically there will be a constant mass of organizations and a constant fraction of them will be of type 1 (i.e., in the low demand state with inefficiency $\bar{\phi}$ ). In view of this we always consider the initial fraction of type 1 organizations to correspond to this fraction. We normalize the total mass to equal 1 and hence assume that $\mu_{10}=\lambda^{l} /\left(\lambda^{l}+\pi^{l}\right)$. As noted earlier, however, at any given point the distribution of the remaining organizations between type 2 and type 3 will be influenced by the previous history of realizations of $\varepsilon_{2}$, and we therefore consider different scenarios for how this remaining mass is allocated across type 2 and type 3 organizations.

For the paths shown in Figure 1 we have set $e^{h}=0.1$ and $e^{f}=10$. Setting $e^{h}=0.1$ amounts to assuming that the accumulated increases in $\varepsilon_{2}$

8 One could interpret this reduced form as reflecting a log linearization of the individual demand for labor functions. over the 20 periods would increase aggregate employment by roughly 4 percent over the course of 20 periods, holding all else constant. We set $\varepsilon^{f}=10$, implying that successful reorganization leads to a reduction in employment of roughly 10 percent. We set $\lambda^{l}=\pi^{l}=0.0025$, implying that over the course of the 20 periods the accumulated probability of failure for a large organization or success for a small organization is roughly 5 percent. Finally, we set $\pi^{e}=0.05$, which implies an expected duration of 20 periods for successful reorganization. Although we have offered these quantitative guides to thinking about the parameter selections, we also emphasize that this example is purely illustrative. We leave a rigorous quantitative assessment of the economic mechanisms described here for future work.

Figure 1 shows the employment paths that result for three different initial values of $\mu_{2}$. In each case, the curve represents deviations from means for each path to focus attention on the implications for timing. The figure shows that as $\mu_{20}$ increases it takes longer to reach the turning point of employment. This result is intuitive. The greater the value of $\mu_{20}$, the greater is the total amount of reorganization that needs to be done. As this reorganization takes place, successful organizations will be shedding labor. This labor shedding is an opposing force to the increases in labor associated with the gradual improvement in the aggregate shock $\varepsilon_{2}$. A key point to note is that in our model, reorganization is potentially a long-lasting process in the sense that in any given period only a given fraction $\pi^{e}$ of the remaining reorganization will be carried out. In fact, it is interesting to note the implications of the extreme case in which $\pi^{e}=1$. In this case all of the "accumulated" reorganization will be carried out in the first period and there will be a large drop in employment, but after this we will see a continual increase in aggregate employment as $\varepsilon_{2}$ increases. Hence, a large amount of accumulated reorganization will simply lead to a very large one-time drop in employment, but will not lead to a delayed turning point for aggregate employment.

To understand the dynamics of the opposing forces, Figure 2 shows the time paths of firing and 


\section{Figure 1}

\section{Effect of Initial Conditions on Employment}

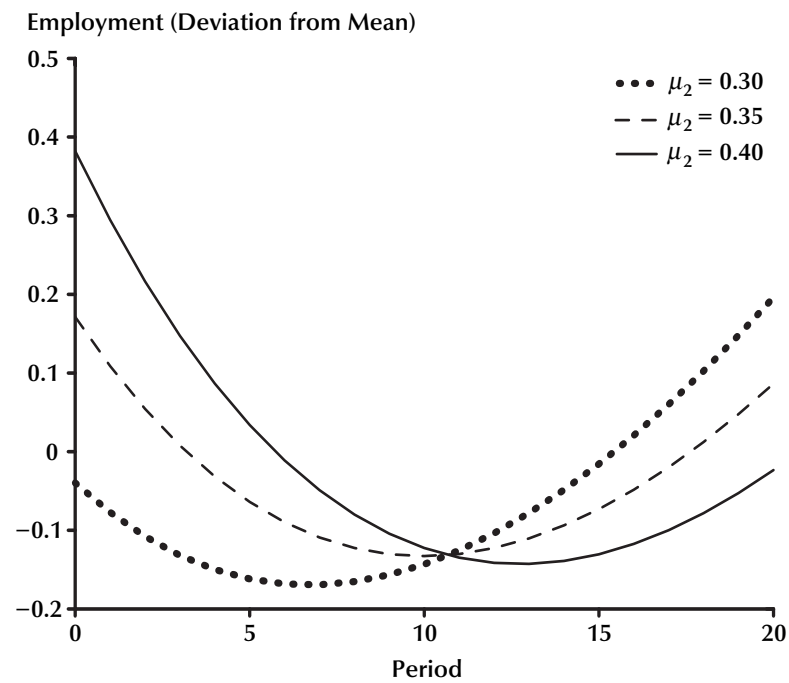

hiring for each of the three scenarios considered in Figure 1. ${ }^{9}$

In all three cases the hiring associated with the improvement in $\varepsilon_{2}$ is constant over time and equal to 0.1 . However, although each economy has the same fundamentals, the variation of the initial distribution of $\mu$ implies that the time path of fires associated with successful reorganization will be different. As Figure 2 shows, the curves are effectively parallel shifts of each other, with the highest value of $\mu_{20}$ associated with the highest level of firing. Because successful reorganization takes time, the path of firing is fairly drawn out. The important feature to note is that aggregate employment will continue to drop as long as the firing curve lies above the hiring curve. And because a higher value of $\mu_{20}$ raises the firing curve but leaves the hiring curve unchanged, it illustrates how restructuring can influence the point at which aggregate employment begins to increase.

We should emphasize that the dynamics that we have just traced out are obviously not defini-

9 An organization that successfully reorganizes may, of course, choose to fire fewer than 10 workers and not hire any new workers; so, when measured, hiring and firing in the economy may not reproduce these curves.

\section{Figure 2}

\section{Initial Conditions and Hiring and Firing}

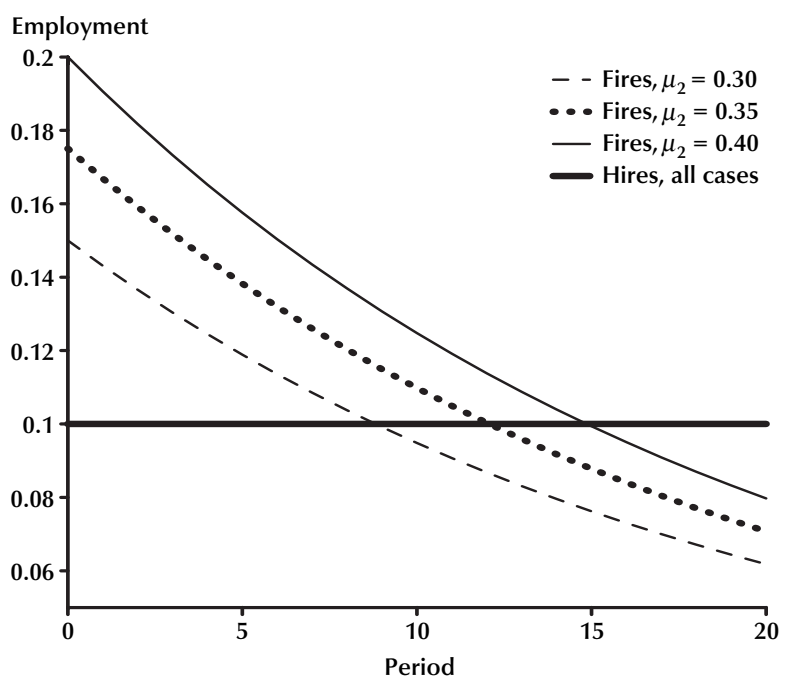

tive predictions of the model. As noted earlier, whether reorganization leads to labor shedding depends on parameter values. The main point we want to emphasize is that the model suggests a mechanism that can produce these types of dynamics.

\section{Firing versus Hiring}

The results of the numerical example reported in the previous section show that aggregate employment growth is slower because many organizations are reducing the size of their workforces. This finding suggests that slow aggregate employment growth should be associated with high separation rates. In fact, Shimer (2005a,b) argues that the slow aggregate employment growth in the recent recovery is due to a low rate of hiring and not to a high rate of separations, including layoffs. In this subsection we discuss how our mechanism could be made consistent with this observation. First note that the curves that we labeled as hires and fires do not actually correspond to their counterparts in the data. Rather, these two curves simply reflect two different forces, one leading to lower employment and one leading to greater employment. If the force 
leading to lower employment called for a decrease of ten workers in an organization and the force leading to higher employment called for an increase of eight workers in that same organization, then we would expect this to show up as a situation with zero hires and two separations.

We argue here that a simple extension of our model can potentially explain why it is low hiring rather than high separations that seems to be the proximate cause of the slow employment growth. If an organization finds itself with too many workers, but expects that over time these workers will be needed, then if the workers possess some valuable organization capital it may be optimal for the firm to simply keep the workers around and let any decreases in employment occur through attrition. This policy could produce a pattern of relatively stable separation rates coupled with an extended period of very low hiring rates. This possibility would become even more relevant if the organizations that grew during the preceding expansion are also the ones that are expected to grow the most in the near future, because they would then represent both the organizations with the most unneeded labor currently and the ones most expected to expand their labor forces in the near future.

\section{General Equilibrium Considerations}

Although our analysis has considered the decision problems of only individual organizations and then aggregated holding wage and interest rates constant, it is worthwhile to discuss how general equilibrium considerations could possibly affect the types of outcomes that we are emphasizing. In particular, it is important to emphasize this issue in the context of the literature related to the work of Caballero and Engel (1999) referred to in the introduction. In that paper, they argue that changes in the distribution of individual firm state variables is important in influencing how the economy responds to shocks. However, the work of Veracierto (2002) and Thomas (2002) show that, in general equilibrium versions of the model, the effects of interest rate movements basically offset the partial equilibrium effects.

There are two main issues that arise. The first concerns how changes in prices might impact the incentives for intertemporal substitution in our decision problem, as represented in our key analytic result showing the existence of a reservation value of $\varepsilon_{2}$ for the reorganization decision. With constant wages and interest rates, reorganization will be shifted away from periods of high economic activity and toward periods of low economic activity. If real wages are procyclical, they could generate an opposing force to our intertemporal substitution. If wages are higher in periods of high economic activity and shocks are persistent, then this produces a cost of not reorganizing that is procyclical. Simply put, the benefit of shedding labor is greater if wages are higher.

General equilibrium effects could also operate through changes in the real interest rate. However, if one views the case of procyclical real interest rates as the case of primary interest, then this effect will actually reinforce our result. If current real interest rates are high, then current-period costs are amplified and future benefits are attenuated, increasing the incentive to postpone reorganization in good times.

One could plausibly argue that some other margins that we have assumed to be constant over time would also exhibit variability over the cycle. For example, although we assumed that transition probabilities are constant over time, one could argue that the probability of a small-scale organization becoming successful increases in good times (i.e., that $\pi^{l}$ is higher in good times). This aspect by itself would tend to accentuate the effects that we have emphasized, because this will lead to a larger buildup of type 2 organizations during good times. Similarly, if entry is higher in expansions, then this aspect will also tend to accentuate the buildup of type 2 organizations.

A second issue that must be addressed in a more complete model is why the workers that are being released due to restructuring do not find employment somewhere. One possible channel is standard intertemporal substitution effects. When an organization restructures, the shift of managerial time away from production and toward restructuring leads to a decrease in the marginal product of labor. A second channel that is not in our model but could be important is that the organ- 
izations with the greatest expected increases in employment in the future may be those that have recently experienced large increases. If this is true, it could be that the organizations that decide to restructure are the same organizations that will eventually add the most workers. One could imagine a more detailed model in which an organization does not add to its existing labor force at the same time that it is trying to reorganize. Hence, the decision to reorganize is implicitly a decision to postpone new hires. Last, if one were to imbed our model into a model in which it takes time for workers to move from one organization to another, then a long-lasting increase in separations would also lead to a long-lasting decline in employment.

\section{A CLOSER LOOK AT JOBLESS RECOVERIES}

In this section, we argue that the insights derived from the preceding discussion may be relevant for understanding some features of business cycle dynamics and that in particular they may be very relevant for the discussion of the phenomenon that has become known as the jobless recovery. As noted in the introduction, many individuals have coined the term "jobless recovery" to describe the apparent slow growth in employment following the troughs of the two most recent recessions, in 1991 and 2001. Viewed in a broader perspective, the obvious implication of such a description is that not all business cycles are alike, which is an old and recurring theme in the business cycle literature. Burns and Mitchell (1946) were among the first to systematically measure the business cycle and argued that business cycles bear a remarkable similarity to each other along many dimensions. In particular, they developed the notion of a reference cycle to represent the "typical" business cycle. Influenced by this work, Lucas (1977) argued that a key stylized fact is that all business cycles are the same from the perspective of qualitative comovement of series. At the same time, there are many instances in which researchers have argued that some particular business cycle exhibits properties that distinguish it from its predecessors, while others have argued that the business cycle phenomenon is slowly changing over time. ${ }^{10}$

The discussion of the previous section suggested that after the end of a long expansion, employment may take longer to start to increase once again. This argument is consistent with the fact that each of the past two recessions has exhibited a relatively long period before employment began to increase, because each of the past two expansions has been extremely long by historical standards. However, there is another episode in the postwar period that would seem to be relevant and that is the recession of 1969-70, which also followed a very long expansion. If the channel that we point to is quantitatively important, then this period should also have produced a "jobless recovery." The goal of this section is to argue that the evidence is indeed consistent with this prediction. In particular, we will argue that there are three recessions in the postwar period that stand out as distinct from the others in terms of the dynamics for employment in the subsequent recovery: 1969, 1991, and 2001. The material presented here draws on the results presented in Koenders (2005), which provides a much more thorough analysis.

\section{A Review of Schreft and Singh}

It is useful to begin with a summary of the analysis of Schreft and Singh (2003). They carry out the following calculation: They start with seasonally adjusted data for employment from the Bureau of Labor Statistics Establishment Survey and then identify the level of employment at each of the National Bureau of Economic Research (NBER) turning points that corresponds to the end of a recession. For each recovery, they plot the percentage change in employment from the turning point that occurs over the subsequent 12 months. Figure 3 is equivalent to the figure that they produce except that we have included the two recessions from the 1950s in our analysis and we have time-aggregated the employment data to quarterly frequency.

But our Figure 1 tells the same story as Chart 1

${ }^{10}$ A related but distinct issue is the extent to which business cycles have become less frequent. 


\section{Figure 3}

\section{The Schreft-Singh Finding}

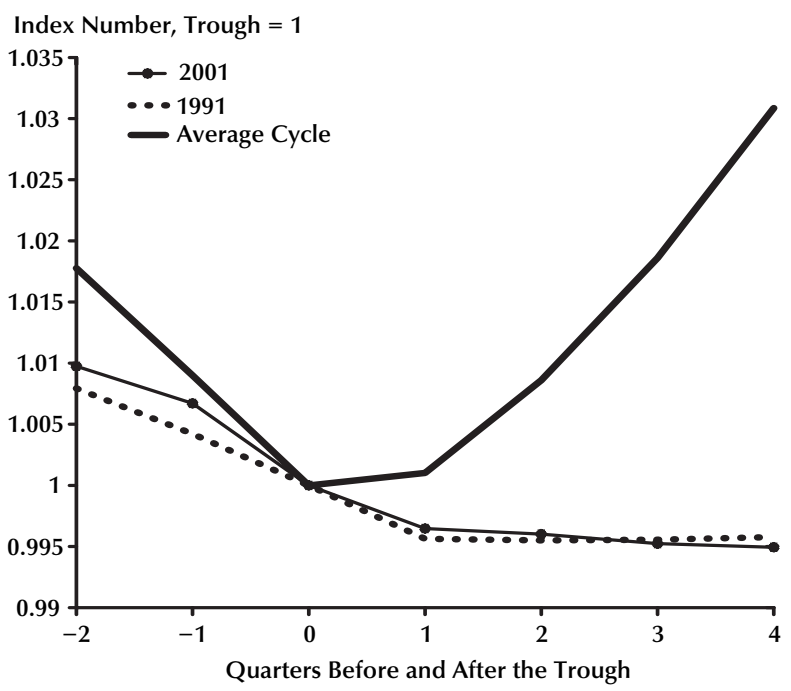

in their paper. Whereas the typical recovery shows steadily rising employment, with an increase of more than 3 percent in the first year of the recovery, the two most recent recessions show employment decreasing in each of the four quarters following the turning point. While this picture certainly suggests that the two recent recoveries are different from the average of the preceding ones, it obviously does not tell us whether there are previous episodes that also resemble the two recent ones. For our purposes we are particularly interested in whether the recovery that began in 1970 also displays this pattern. Figure 4 repeats the analysis of Figure 3 except we now consider three recoveries individually and compare them with the average of the remaining five recoveries. (Throughout this analysis we ignore the recovery in the early 1980s because it was so short-lived.)

This figure suggests that the recovery that began in 1970 is much more similar to the average recovery than it is to the recoveries following the two most recent recessions. One can repeat this analysis for the other recoveries as well, and one obtains a similar pattern in each case. Based on this analysis, one would be led to conclude that it is only the two most recent recoveries that

\section{Figure 4}

\section{The 1970 Recovery (Schreft-Singh Method)}

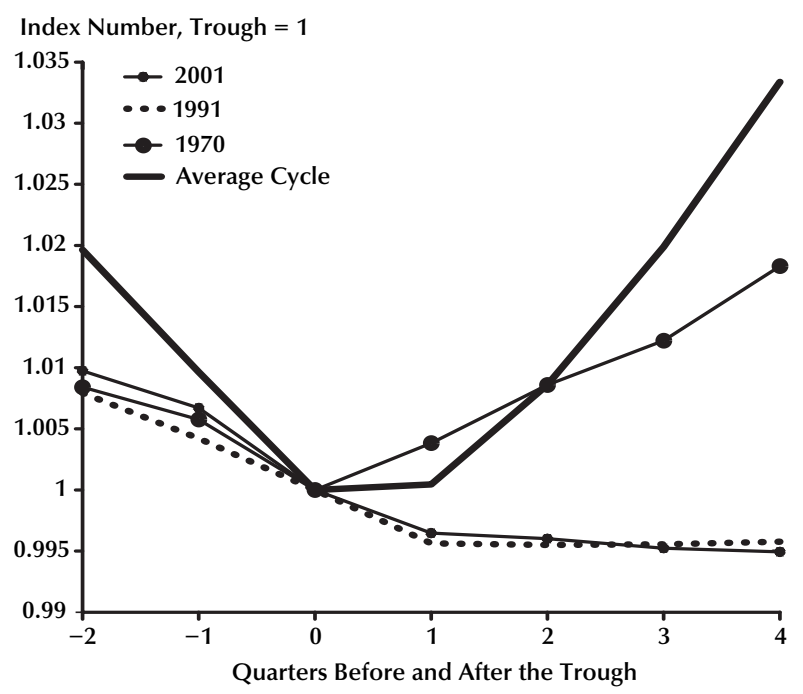

have had particularly distinctive employment dynamics.

However, there are several issues we want to raise regarding the Schreft-Singh method of summarizing the data. The first issue is that the Schreft-Singh method is not consistent with modern views of the business cycle. Following Lucas (1977), modern business cycle analysis views the business cycle as deviations from a slowly changing trend. Properties of business cycles should be properties of the component of the time series that corresponds to these deviations from trend. The Schreft-Singh method neglects this consideration in two important regards. First, some recessions are more severe than others. To the extent that recessions are temporary departures from trend, a deeper recession would naturally be expected to be followed by higher subsequent growth in employment. The Schreft-Singh method does not incorporate this feature. Second, their method does not distinguish between movements in the trend and deviations from the trend. If the (raw) level of employment following the trough of a recession starts to increase, how are we to know to what extent we are moving closer to trend? If the trend always increased at the same rate, 


\section{Table 1}

\section{Employment Growth by Decade (percent)}

\begin{tabular}{ccccc}
$\mathbf{1 9 5 0 - 6 0}$ & $\mathbf{1 9 6 0 - 7 0}$ & $\mathbf{1 9 7 0 - 8 0}$ & $\mathbf{1 9 8 0 - 9 0}$ & $\mathbf{1 9 9 0 - 2 0 0 0}$ \\
\hline 20.89 & 26.81 & 23.91 & 17.85 & 17.45
\end{tabular}

this issue would be irrelevant because it would affect all recoveries in the same fashion. However, a key feature of the postwar labor market in the United States is that trend employment growth has fluctuated substantially over time, due both to the entry of the baby boom into the labor market and the increased participation of women. Table 1 illustrates this point by showing the decadal growth rates in employment for the U.S. economy for the five postwar decades.

Table 1 shows that the differences are large: The decadal growth rate in employment during the 1960s is more than one and a half times as large as the decadal growth rates in the two most recent decades. It follows that sorting out relative movements in trend and deviation from trend may be an important consideration in documenting the differential pace of employment growth during recoveries.

Third, the Schreft-Singh method compares the dynamics of recoveries by examining the behavior going forward from the turning point. It is not clear that the turning point is the appropriate comparison point across cycles. In particular, if the downturns preceding the recoveries have been different, it is not clear that behavior should be the same from the turning point forward. In fact, we will argue later that our model suggests that the turning point should not be used as a common reference point.

Having raised some issues about the statistics that Schreft and Singh report, we now describe the method that we use.

\section{An Alternative Look at the Data}

Our method is straightforward and is consistent with current practice in business cycle analysis in terms of documenting properties of cyclical fluctuations. In particular, let $X_{t}$ be a quarterly series that is seasonally adjusted for which we have observations going from period 0 to period $N$. Define $x_{t}$ to be the log of the series $X_{t}$. We define the trend component of $x_{t}$, denoted by $x_{t}^{T}$, by using the Hodrick-Prescott filter. In particular, $x_{t}^{T}$ is the solution to the following optimization problem:

$$
\min _{\left\{x_{t}^{T}\right\}} \sum_{t=1}^{N-1}\left\{\left[x_{t}-x_{t}^{T}\right]^{2}+\lambda\left[\left(x_{t+1}^{T}-x_{t}^{T}\right)-\left(x_{t}^{T}-x_{t-1}^{T}\right)\right]^{2}\right\}
$$

Following the literature, for quarterly data we use a value of $\lambda=1,600$.

The cyclical component of $x_{t}$, denoted by $x_{t}^{C}$, is simply the deviation of $x_{t}$ from its trend value: $x_{t}^{C}=x_{t}-x_{t}^{T}$. Because the series are measured in logs, the cyclical component reflects the percent deviation of the variable from its trend.

Figure 5 repeats the exercise of Schreft and Singh but uses the cyclical component defined previously as opposed to the raw data. In particular, this graph shows the percent change in the cyclical component of employment in each of the four quarters following the NBER turning points. ${ }^{11}$

This figure tells a similar story to the one told by Figure 3, though we note that some details are different. In particular, whereas Figure 3 indicated that in a typical recovery employment begins to grow as soon as the turning point is reached, Figure 5 displays the well-known feature that employment lags gross domestic product (GDP). In particular, this figure shows that in a typical recovery, employment begins to increase one quarter after GDP begins to increase. ${ }^{12}$ (We note that the cyclical component of GDP defined here has the property that the turning point for GDP follow-

\footnotetext{
${ }^{11}$ It is important to note that, whenever one detrends the data, the behavior of the cyclical component at the very beginning and end of the sample is somewhat sensitive to the initial and terminal data points. This implies that the properties of the 2001 recovery may look somewhat different as more data become available.

${ }^{12}$ See, for example, the cyclical properties as reported in Cooley and Prescott (1991).
} 


\section{Figure 5}

\section{The 1991 and 2001 Recoveries (Detrended)}

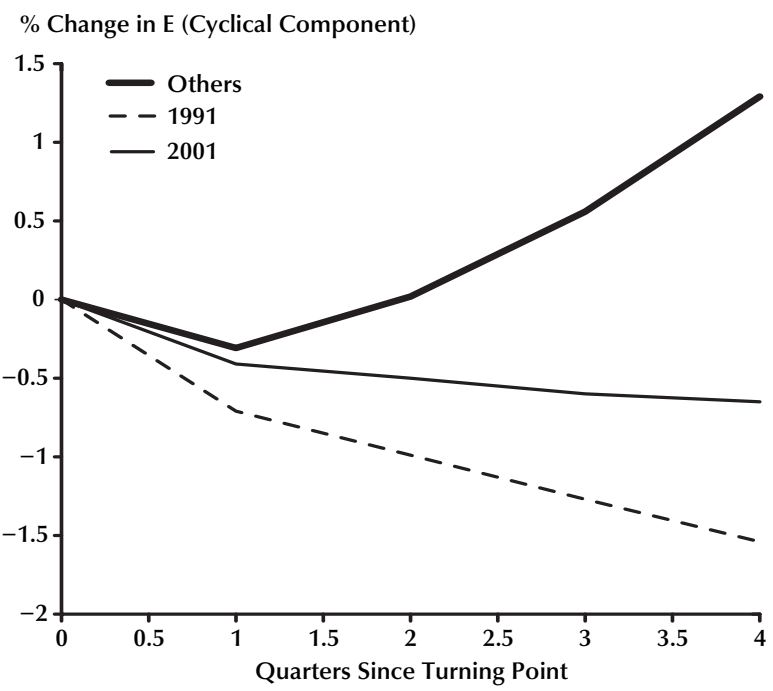

ing each recession coincides with the NBER turning point dates.)

Next, we again ask if the recovery that began in 1970 is similar to the two most recent recoveries. Figure 6 shows the results of carrying out the exercise analogous to that which generated Figure 4-that is, we now consider three individual recoveries and compare them with the average of the other five.

We see that Figure 6 offers a very different conclusion than does Figure 4. Based on analysis of the cyclical component of the employment series, the 1970 recovery also shows that, even one year after the turning point, employment remains below its level at the turning point. While this picture still indicates quantitative differences across the three recoveries, the qualitative behavior is in fact similar.

These figures still suffer from the first problem we mentioned earlier: They do not take into account that the recessions vary quite substantially in their severity, and hence we do not know how much of the variation in growth simply reflects differences in distances from trend. There are many ways that we might normalize business cycles to account for the differing magnitudes.

\section{Figure 6}

\section{Recoveries of 1970, 1991, and 2001 (Detrended)}

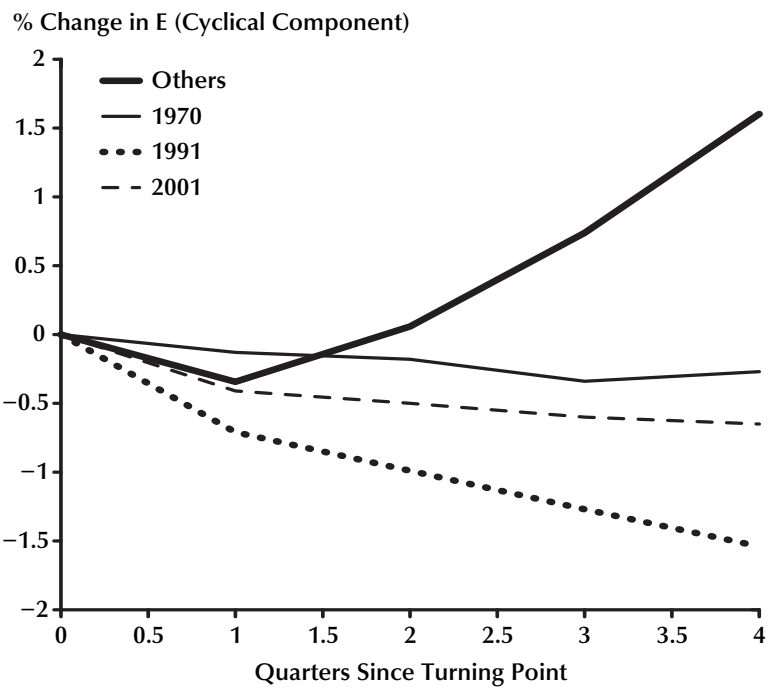

We employ a simple procedure here, which is to normalize by the magnitude of the recession as measured by the maximum percent deviation of output below trend. We then scale all of the employment deviations by dividing through by the absolute value of this number. This calculation is shown in Figure 7.

Qualitatively this figure presents the same conclusions as the earlier figure, but we note that it does affect the quantitative differences across episodes.

One way to summarize the properties of the figures is in terms of the extent to which the turning point for employment lags the turning point for GDP. Table 2 shows the values for each of the post-1950 recessions.

This statistic confirms a property that we saw in the figures presented earlier: Whereas a lag of 0 or 1 quarter is typical for the postwar period, there are three recoveries in which the lag is longer, and all three of these are recoveries from recessions that follow long expansions. This evidence supports our earlier claim about characterizing postwar recoveries. At the same time, Table 2 suggests that there is quite a significant difference between the 1970 recovery and the two most 
Figure 7

\section{Cyclical Employment, Normalized by Magnitude of Trough}

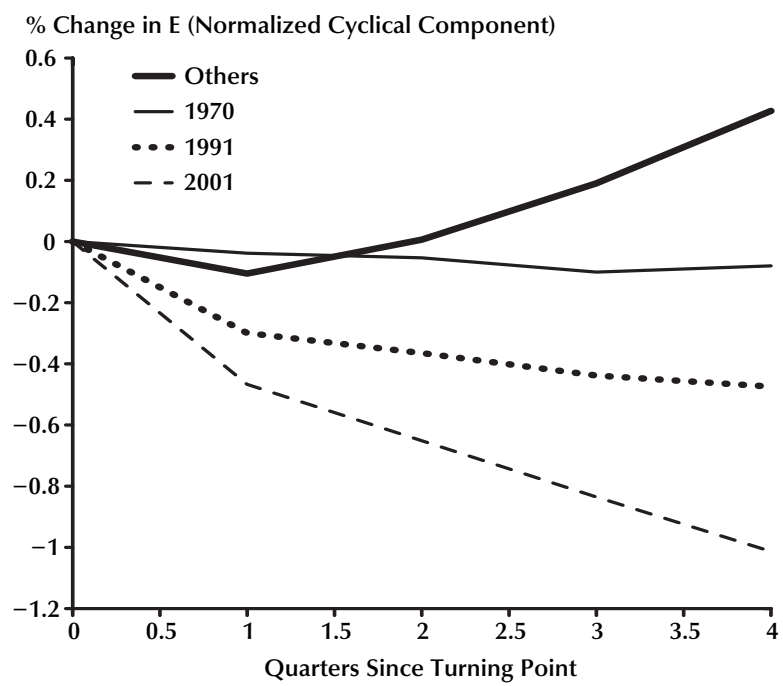

\section{Figure 8}

\section{Comparing the 1970, 1991, and 2001 Recoveries}

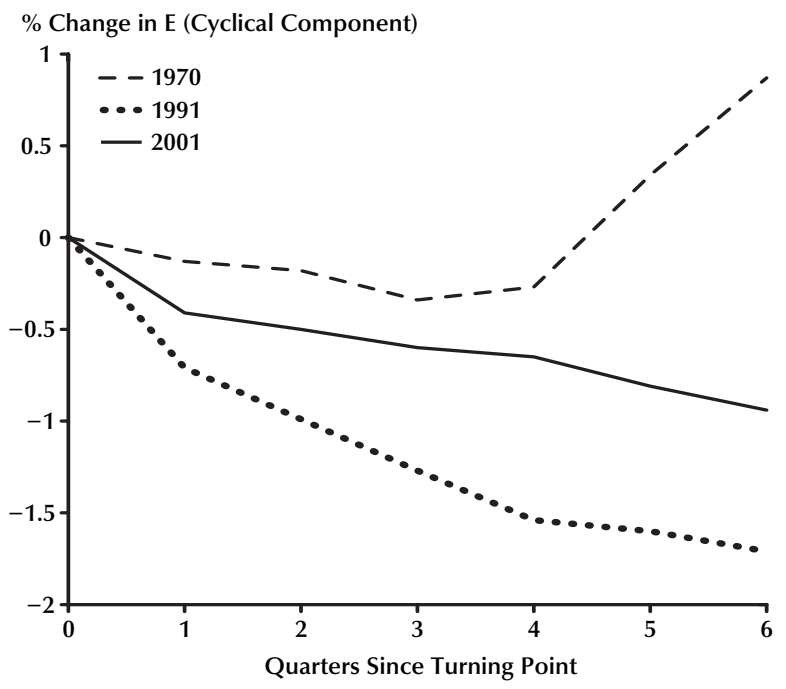

Table 2

Lag in Employment Turning Point Relative to GDP (quarters)

\begin{tabular}{cccccccc}
1954 & 1958 & 1961 & 1970 & 1975 & 1982 & 1991 & 2001 \\
\hline 1 & 0 & 1 & 3 & 1 & 1 & 6 & 7
\end{tabular}

recent recoveries. The lags in the two most recent recoveries are in fact much longer than was experienced in the 1970 recovery. In particular, if we extend the analysis from the four quarters following the turning point to seven quarters, then we obtain Figure 8.

Figure 8 would seem to suggest that the 1970 episode is not so similar to the two most recent ones. What we argue next, however, is that this difference is illusory. In particular, we argue that it is driven by the choice of initial point and that, when this initial point is chosen in a way that we believe is more consistent with the theory laid out earlier in the paper, the differences disappear.

To understand the issue, consider the discussion from the previous section. The key point there was that the time before employment begins to increase is tied to the time required for reorganization to diminish sufficiently. The key point to take away from this analysis is that the turning point is not the point at which reorganization begins. Presumably reorganization starts to take place at some point during the recession preceding the recovery. This possibility is significant because the duration of the recession preceding the turning point differs significantly across recessions. In particular, this period is either average or below average for the two most recent recessions and is much above average for the 1969-70 recession.

To implement this element, we need to have a method for picking out at what point reorganization begins. One possibility would be that it begins when the downturn first begins. However, 
Table 3

Quarters Before Turning Point with GDP Below Trend

\begin{tabular}{cccccccc}
1954 & 1958 & 1961 & 1970 & 1975 & 1982 & 1991 & 2001 \\
\hline 2 & 2 & 2 & 4 & 2 & 4 & 1 & 2 \\
\hline
\end{tabular}

\section{Figure 9}

\section{Recoveries with Alternative Initial Point}

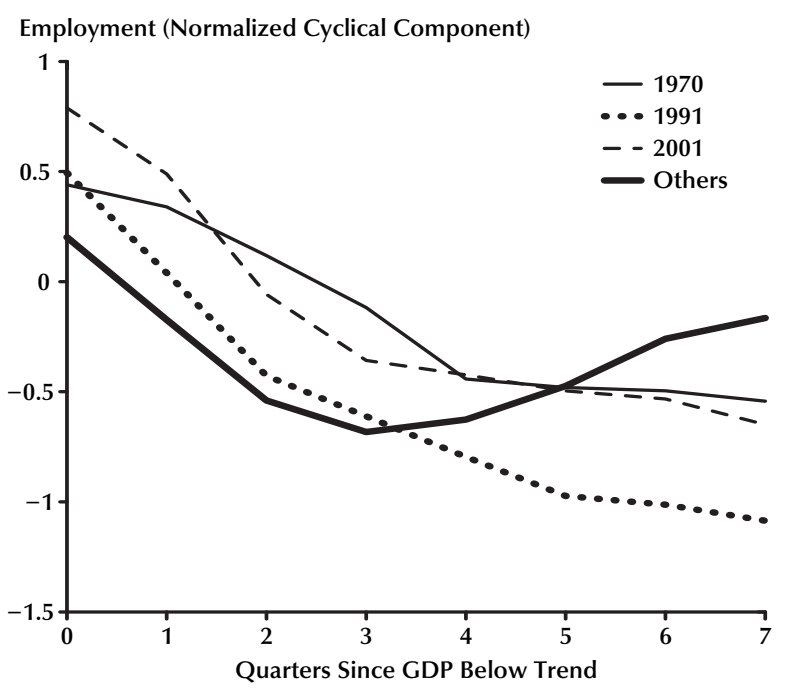

when a recession first begins, output is still quite high above trend and the analytic result that we proved earlier in the paper suggested that it is the level of output that is particularly important. With this in mind, we identify the point at which reorganization begins to be the first quarter in which the cyclical component of output lies below trend. This choice is obviously ad hoc, so the analysis that follows should really be interpreted as illustrating the potential importance of this type of correction. Table 3 shows, with the data, how many quarters this occurs prior to the NBER turning point for each of the eight recessions.

Table 3 indicates that the typical number of quarters that GDP is below trend prior to reaching its turning point is two, but that in 1970 this value was four, and in 1991 it was only one.

What we do next is to repeat our earlier analy-

\section{Figure 10}

\section{Behavior of Aggregate Hours}

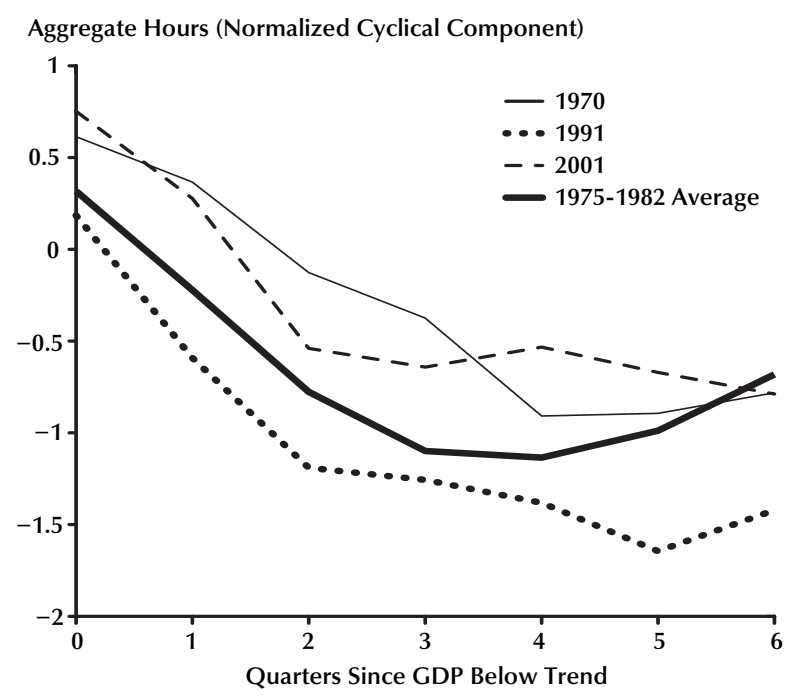

sis, but instead of using the turning point as the initial condition for each recession, we use the period as indicated in Table 3. Once again we continue to normalize using the magnitude of the drop in GDP as our scale factor. Figure 9 shows the average of the five "typical" recessions versus each of the three more prolonged recoveries.

It shows that the three recessions all stand out as different from the average of the others.

To this point we have focused on employment dynamics. Employment is simply one dimension along which labor input can vary. An important issue is the extent to which different behavior of employment across cyclical episodes also represents differences in labor input. Alternatively, it could be that the dominant difference across episodes is the compositional changes in labor input. More generally, one should also be con- 


\section{Figure 11}

\section{Productivity per Employee in the 1970, 1991, and 2001 Recoveries}

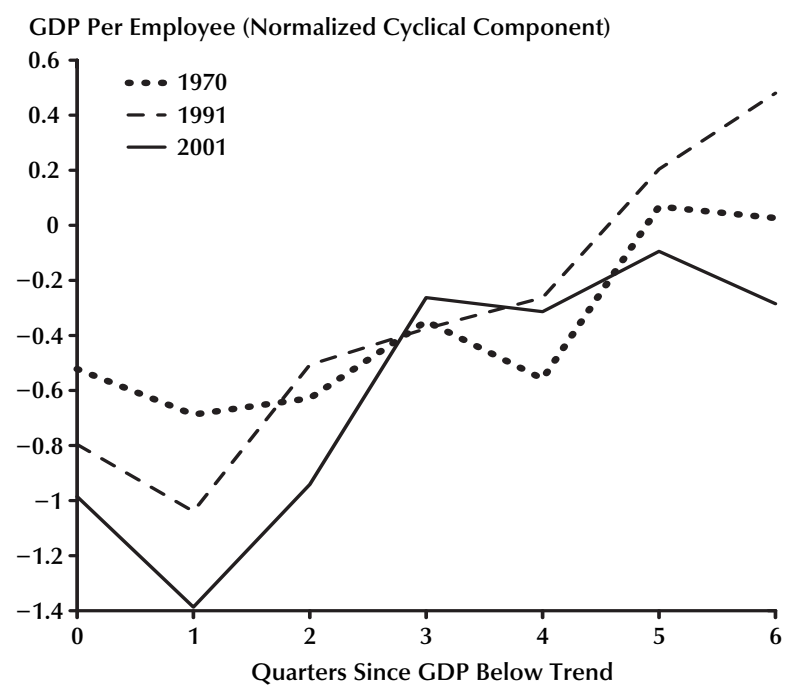

cerned about measuring effective labor input rather than simply bodies or hours. We leave a more careful analysis of these issues for future work, but do want to present at least one piece of evidence to suggest that the differences in the behavior of employment that we have noted also extend to the behavior of aggregate hours. We have hours data only from 1964 on, so this analysis has only five cyclical episodes to compare. Figure 10 compares the three recoveries that we have focused on with the average of the other two recoveries. Period 0 in this figure refers to the first period in which GDP drops below trend prior to the associated recovery.

While the basic pattern in this figure is qualitatively similar to the one found in our graphs for employment, it is also true that the differences are much smaller in this graph than in the employment graphs. We infer from this that a more careful study of the behavior of labor input along the intensive and extensive margins is warranted.

Last, it is of interest to examine the behavior of productivity across the cyclical episodes. Our model predicts that when organizations switch from producing to reorganizing they experience

\section{Figure 12}

\section{Comparison of Productivity per Employee Across Recoveries}

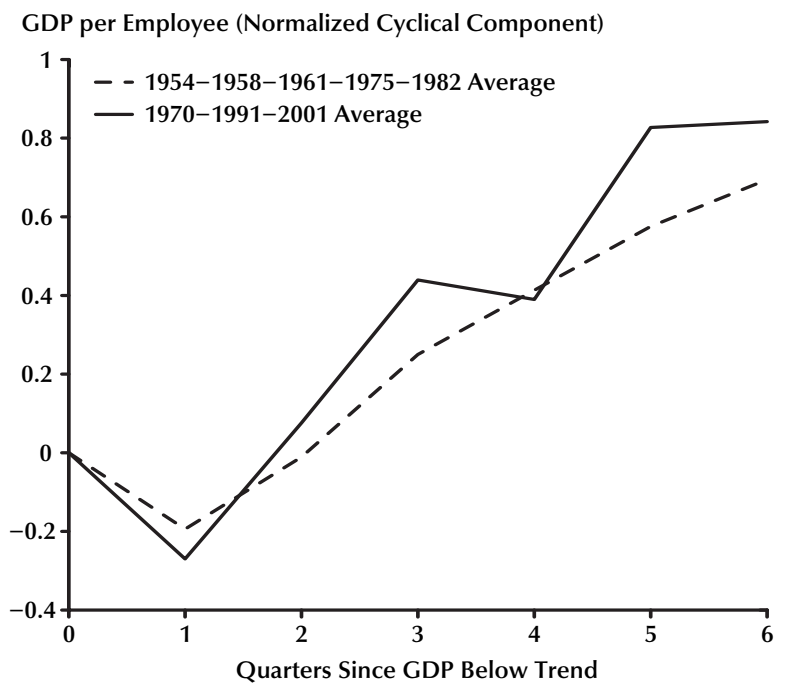

a decrease in productivity. However, as time passes and successful reorganization occurs, we should see increases in productivity. Having said this, we also feel that a large degree of caution need be taken with respect to assessing the implications for productivity. We have implicitly assumed that aggregate fluctuations in our model are driven by shocks to the demand for the output of each organization. While this is a convenient formulation for our analysis, it could be that the increase in demand is driven by improvements in product quality, which in a more complete model would also show up as productivity changes.

Having offered this caveat, we now turn to analyze the dynamics of productivity. Because hours data are available only since 1964, we use two different measures of productivity. First we compare output per worker to be able to use all eight recessions and then use output per hour to compare the five most recent recessions. Figure 11 shows how productivity per worker evolves in the three recoveries of interest.

Note that in all cases productivity drops in the initial period but then increases thereafter. 


\section{Figure 13}

\section{Comparison of Productivity per Hour Across Recoveries}

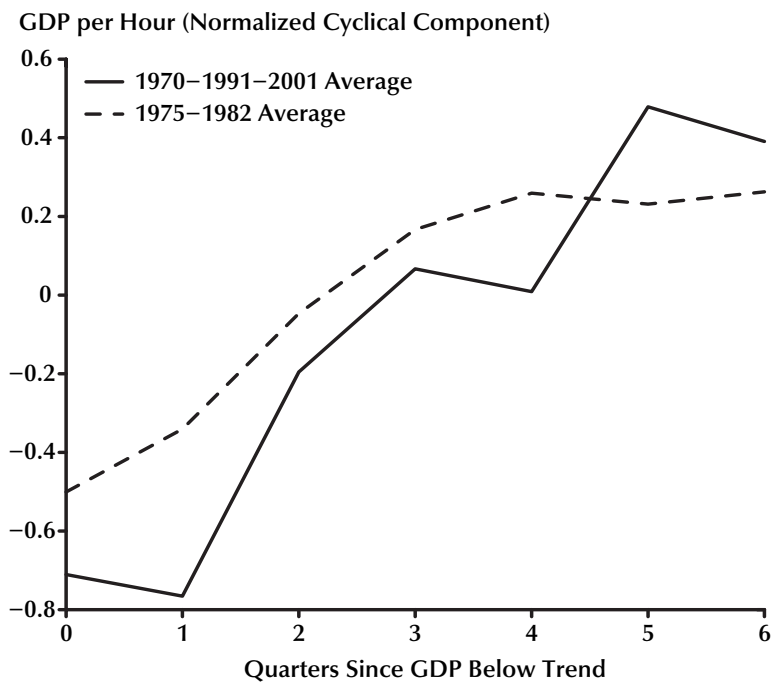

While the magnitudes are somewhat different across the three episodes, the pattern is quite similar. At a very qualitative level this pattern seems to accord well with the implications of our model described previously. Next we consider how productivity changes vary across the different types of recoveries. Figure 12 compares the average of these three recoveries with the average across the other five recoveries.

Both curves show the same qualitative behavior. The average of the three recoveries following long expansions does indeed have a slightly larger drop in the initial period and does show somewhat higher subsequent growth. Qualitatively, these patterns are consistent with what one would expect from our model, though the quantitative differences do not seem that large.

Next we compare the behavior of productivity per hour for the post-1964 recoveries.

Figure 13 shows the same two features: The three recoveries associated with recession following long expansions have a somewhat larger initial drop in productivity and subsequently experience somewhat higher growth.

\section{CONCLUSION}

We have highlighted a simple economic mechanism that we argue may be relevant for understanding the different behavior of labor market aggregates across business cycles. The model stresses two key effects. First, it argues that internal organizational dynamics are affected by aggregate shocks. Second, it stresses that the situations of organizations affect the manner in which the economy responds to aggregate shocks. In periods of high economic activity, organizations postpone structural changes to take advantage of current opportunities. But once an organization begins the process of restructuring, it is less likely to hire workers and more likely to release workers. These effects suggest the possibility that long expansions will be followed by recoveries in which employment starts to increase much later than output.

We then assess this link by studying eight U.S. recessions in the post-1950 period. We argue that all three recoveries from recessions that followed long expansions exhibit the pattern of a long delay in the turning point for aggregate employment. This finding contrasts sharply with the characterization that it is the two most recent recoveries that are distinct.

While we think this work is suggestive, we must also emphasize that it is indeed only suggestive. A more rigorous quantitative assessment of the economic mechanism is called for, as is a more thorough analysis of the data.

\section{REFERENCES}

Aaronson, Daniel; Rissman, Ellen R. and Sullivan, Daniel G. "Further Evidence on Sectoral Reallocation and the Jobless Recovery. " Unpublished manuscript, Federal Reserve Bank of Chicago, 2004.

Andolfatto, David and MacDonald, Glenn M. "Jobless Recoveries.” Working paper, 2004.

Bertschek, Irene and Kaiser, Ulich. "Productivity Effects of Organizational Change: Microeconometric Evidence.” Unpublished manuscript, 2001.

Burns, Arthur F. and Mitchell, Wesley C. Measuring 
Business Cycles. New York: National Bureau of Economic Research, 1946.

Caballero, Richard and Engel, Eduardo. "Explaining Investment Dynamics in U.S. Manufacturing: A Generalized (S,s) Approach.” Econometrica, July 1999, 67(4), pp. 783-826.

Cole, Harold L. and Ohanian, Lee E. "New Deal Policies and the Persistence of the Great Depression: A General Equilibrium Analysis." Journal of Political Economy, August 2004, 112(4), pp. 779-816.

Cooley, Thomas F. and Prescott, Edward C. "Economic Growth and Business Cycles,” in Thomas F. Cooley, ed., Frontiers of Business Cycle Research. Princeton, NJ: Princeton University Press, 1991, pp. 1-38.

Groshen, Erica L. and Potter, Simon M. "Has Structural Change Contributed to a Jobless Recovery?” Federal Reserve Bank of New York Current Issues in Economics and Finance, August 2003, 9(8).

Hall, Robert E. "Labor Demand, Labor Supply and Employment Volatility," in Olivier Blanchard and Stanley Fischer, eds., NBER Macroeconomics Annual 1991. Cambridge, MA: MIT Press, 1991, pp. 17-61.

Hopenhayn, Hugo A. "Entry, Exit and Firm Dynamics in the Long Run.” Econometrica, September 1992, 60(5), pp. 1127-50.

Hopenhayn, Hugo A. and Rogerson, Richard. "Job Turnover and Policy Evaluation: A General Equilibrium Analysis." Journal of Political Economy, October 1993, 101(5), pp. 915-38.

Kliesen, Kevin L. "The 2001 Recession: How Was It Different and What Development May Have Caused It?” Federal Reserve Bank of St. Louis Review, September/October 2003, 85(5), pp. 23-38.

Koenders, Kathryn. "Long Expansions and Slow Recoveries: A Closer Look at Employment Fluctuations." Unpublished manuscript, Arizona State University, 2005.
Krusell, Per and Smith, Anthony A. "Income and Wealth Heterogeneity in the Macroeconomy." Journal of Political Economy, October 1998, 106(5), pp. 867-96.

Lilien, David M. "Sectoral Shifts and Cyclical Unemployment." Journal of Political Economy, August 1982, 90(4), pp. 777-93.

Lucas, Robert E. Jr. "Understanding Business Cycles.” Carnegie-Rochester Series on Public Policy, 1977, 5, pp. 7-29.

Lucas, Robert E. Jr. "On the Size Distribution of Business Firm.” Bell Journal of Economics, Autumn 1978, 9(2), pp. 508-23.

Schreft, Stacey L. and Singh, Aarti. "A Closer Look at Jobless Recoveries.” Federal Reserve Bank of Kansas City Economic Review, Second Quarter 2003, 88(2), pp. 45-73.

Shimer, Robert. "The Cyclicality of Hires, Separations, and Job-to-Job Transitions.” Federal Reserve Bank of St. Louis Review, July/August 2005a, 87(4), pp. 493-507.

Shimer, Robert. "Reassessing the Ins and Outs of Unemployment.” Working paper, 2005b.

Thomas, Julia J. "Is Lumpy Investment Relevant for the Business Cycle?" Journal of Political Economy, June 2002, 110(3), pp. 508-34.

van Rens, Thijs. "Organizational Capital and Employment Fluctuations.” Job Market Paper, Princeton University, 2004.

Veracierto, Marcelo L. "Plant Level Irreversible Investment and the Business Cycle." American Economic Review, March 2002, 92(1), pp. 181-97. 
